\title{
A DÍADE VIRTÙ-FORTUNA NA FUNDAÇÃ̃o E MANUTENÇÃO DA ORDEM EM NICCOLÒ MACHIAVELLI
}

\author{
Jean Felipe de Assis ${ }^{1}$ \\ Universidade do Estado do Rio de Janeiro (UERJ) \\ https://orcid.org/0000-0001-9292-9228 \\ E-mail: jeanfelipe@hcte.ufrj.br
}

\section{RESUMO:}

O par Fortuna-Virtù é discutido nas diversas análises críticas do pensamento de Machiavelli e, embora tais termos possuam origens e tradições bem determinadas ao longo do pensamento latino, principalmente específicas considerações antigas e medievais em algumas recepções durante o humanismo cívico, suas características elusivas ao longo das argumentações de Machiavelli são mantidas, possibilitando inúmeros debates acadêmicos. Diante da ambivalência e da ambiguidade da ideia de Virtù perante relevantes e variadas tradições, contínuas buscas por clarificação são feitas ao longo do corpus do secretário florentino, associando o termo a outras importantes e centrais reflexões, e.g., desiderio, stato, forza. A instabilidade política, as forças além do controle humano, a imponderabilidade das ações civis são temas recorrentes nas concepções sobre a Fortuna em variadas argumentações desse autor. Em aberto diálogo com os humanistas cívicos que enfatizam maior participação política e social, mesclando embasamento racional, consideração moral e as discussões sobre as formas dos regimes políticos, esse escritor apresenta uma concepção historiográfica, a revigorar tradições do mundo antigo, na criação de uma ordem civil mediante a Virtù, a qual demanda comprometimento pessoal e público na exaltação das potencialidades e dos limites humanos. Reinserir a relevância da paridade entre Fortuna e Virtù em Machiavelli é um passo relevante no combate a leituras anacrônicas. Assim, analisar-se-ão os exemplos mais significativos dos fundadores e dos sustentadores da ordem civil destacados nos textos discursivos do florentino, e.g., Romulo, Numa, Moisés, Cesare Bórgia, Castruccio Castracani. Ao estudar as imagens da Fortuna, em face das concepções políticas e antropológicas do autor, discutir-se-á a centralidade da díade Virtù-Fortuna no desenvolvimento argumentativo de algumas ideias principais desse famoso pensador político.

PALAVRAS-CHAVE: Machiavelli; Fortuna; Virtù.

\section{FOUNDING AND MAINTAINING CIVIC ORDER THROUGH THE FORTUNA-VIRTÙ PAIR IN NICCOLÒ MACHIAVELLI}

\begin{abstract}
:
Eminent critical evaluations on Machiavelli's thought discuss the Fortuna-Virtù pair. Even though such terms share wellknown origins and traditions throughout Latin literary historiography, especially ancient and medieval receptions during civic humanism, their elusive features persist in Machiavelli's arguments, enabling numerous academic debates. While the idea of Virtù maintain its ambivalence and ambiguity throughout these relevant and varied textual evidences, continual pursuits for clarification are made throughout the Florentine secretary's corpus, associating the term with other important and central concepts, e.g., desiderio, stato, forza. Political instabilities, forces beyond human control, unpredictability of civil actions are recurring themes in Machiavelli's conceptions of Fortune. In open dialogue with civic humanists who emphasize a crescent political and social participation, blending rational reflections, moral consideration, as well as discussions about different forms of regimes, this author exposes a historiographical conception, reinvigorating ancient traditions, in the creation of a civil order. This demands Virtù, a personal and public commitment in the exaltation of human potentialities and limits. Reinserting the relevance of a parity between Fortuna and Virtù in Machiavelli is a relevant step for avoiding anachronistic readings. Thus, the most significant examples of civic founders and maintainers of civic order are investigated, e.g., Romulo, Numa, Moses, Cesare Borgia, Castruccio Castracani. By studying the images of Fortune, in face of Machiavelli's political and anthropological conceptions, the argumentative development of some main ideas of this famous political thinker sustains the centrality of the Virtù-Fortuna dyad.
\end{abstract}

KEYWORDS: Machiavelli; Fortuna; Virtù.

\footnotetext{
${ }^{1}$ Doutor em História e Filosofia das Ciências pela Universidade Federal do Rio de Janeiro (UFRJ), Rio de Janeiro - RJ, Brasil. Professor substituto da Universidade do Estado do Rio de Janeiro (UERJ), Rio de Janeiro - RJ, Brasil. Bolsista do(a): Fundação Carlos Chagas Filho de Amparo à Pesquisa do Estado do Rio de Janeiro (FAPERJ), Rio de Janeiro - RJ, Brasil.
}

ASSIS, Jean Felipe de. A díade virtù-fortuna na fundação e manutenção da ordem em Niccolò Machiavelli. Griot : Revista de Filosofia, Amargosa - BA, v.20, n.2, p.309-331, junho, 2020. 
A eminência da paridade entre Virtù e Fortuna para a compreensão do pensamento de Machiavelli é largamente atestada por seus comentadores ${ }^{2}$. Existem inúmeras tradições latinas e medievais que discutem a Fortuna e as ações humanas possíveis, fornecendo aos autores renascentistas uma série de imagens e reflexões exploradas por Machiavelli em suas variadas obras. Compreender os discursos intelectuais que relacionam esses termos no Umanismo e no Rinascimento italianos permite uma apreciação das obras de Machiavelli em sua situação particular e a partir de suas concepções intelectuais. As constantes dualidades e interações entre Fortuna e Virtù são constatadas em variados autores do humanismo cívico italiano. Diferentes escritores, e.g., Petrarca, Salutati e Bruni, enfatizam maior participação política e social, mesclando embasamento racional, consideração moral e as discussões sobre as formas dos regimes políticos ${ }^{3}$.

As inter-relações entre justiça, Liberdade e ambição, juntamente a novas tendências historiográficas a revigorar tradições do mundo antigo, demandam comprometimento pessoal e público, na exaltação das potencialidades e dos limites humanos ${ }^{4}$. Evidencia-se, portanto, a relação constante entre Virtù e Fortuna ao longo do desenvolvimento intelectual medieval, em especial algumas tradições latinas que ganharam grande destaque no Rinascimento Italiano. A proclamação de uma via ativa no humanismo cívico italiano requer uma ação intelectiva vigorosa para as melhores formas de organização social nas quais os ideais antigos poderiam se atualizar em uma possível glória presente. $\mathrm{O}$ tema da Liberdade, em conexão com o pensamento Republicano de Machiavelli, é um dos exemplos ilustres deste período: opõe-se a uma tradição considerada omissa e sem força ${ }^{5}$. A participação Política e a consistência racional das ações humanas são harmonizadas por concepções teóricas e práticas em que as melhores formas de organização social abranjam uma via contemplativa e uma premissa ativa ${ }^{6}$. As diversas tradições do humanismo cívico, correntes de pensamento e desenvolvimento de autores particulares, possibilitam uma discussão sobre os variados meios de compreensão das concepções

\footnotetext{
${ }^{2} \mathrm{O}$ par Fortuna-Virtù é discutido nas diversas análises críticas do pensamento de Machiavelli e, embora tais termos possuam origens e tradições bem determinadas ao longo do pensamento latino, principalmente específicas considerações medievais e reflexões do humanismo cívico, eles também mantêm suas características elusivas ao longo das argumentações de Machiavelli, possibilitando inúmeros debates acadêmicos (MANSFIELD, 1998, 6-52; SKINNNER, 2004, 160-186; POCOCK, 1975, 31-48; WHITFIELD, 1943, 222-225; PRICE, 1973, 315-345; PRICE, 1977, 588-631; PRICE, 1982, 383-445). Deveras, os diversos trechos em que a ideia de Virtù se apresenta possuem uma variedade de significados, os quais "atordoam" ao leitor e gera uma suspeita de "inconsistência". Entre os temas centrais relacionados, a busca por glória, o vigor, a audácia e a possibilidade de efetuar o aparentemente mal quando necessário se destacam (GILBERT, 1951, 53-55). Esse autor chama a atenção para as características medicinais, associadas à força vital de um organismo para o seu bom funcionamento, considerando que Machiavelli enfatiza a força vital e o funcionamento do corpo social.

${ }^{3}$ A idealizada passagem de uma via contemplativa para um entendimento ativo no decorrer do humanismo cívico italiano não é facilmente sistematizada e requer uma erudição histórica a destacar experiências e percepções particulares ao longo do tempo nos autores supracitados (POCOCK, 1975, 3-155).

4 Atesta-se que a harmonia alcançada pelos antigos poderia ser reestabelecida pelo estudo de suas obras literárias e artísticas, necessitando desejo, disposição e ações concretas dos contemporâneos para a reconquista das riquezas e dos tesouros expressos pelo pensamento clássico (GARIN, 1978, 16-28).

${ }^{5}$ As concepções a respeito da Liberdade devem considerar as características coletivas e individuais, mas também as constituições internas e externas às comune. Ademais, conforme salienta Newton Bignotto (p. 21-28), as formas dos regimes políticos, o controle à corrupção e a ideia de um tempo circular são considerações importantes para uma compreensão abrangente da Liberdade em Machiavelli (BIGNOTTO, 1991, 21-28; 38-51). No caso particular das principais correntes do pensamento cívico italiano, a discutir as noções de Liberdade, exige-se uma compreensão histórica de Florença e das tradições intelectuais subjacentes ao Humanismo Cívico, sobretudo devido às recepções - assimilações e transformações - de autores particulares (45-49). Os desenvolvimentos variados sobre a Liberdade tendem a preservar uma harmonia entre ação e pensamento, aproximando-se gradativamente ao que seria posteriormente entendido como realismo político. Ao se discutir as formas de governo, busca-se estipular independências e autonomias externas e, simultaneamente, discutir as organizações internas às comune, e.g., sistemas, atividades, acessos, princípios de igualdade. As constantes guerras demandam práticas políticas que visem à unidade interna necessária para o acesso e a conservação da Liberdade, independente dos sistemas políticos escolhidos, mas que considerem a "necessità" e a "ragione", as quais posteriormente poderiam assumir forma republicanas (BARON, 1993, 443-447). Há, neste fervor político-intelectual, uma variedade imensa de práticas econômicas e culturais a perpassarem todos os níveis do tecido social (BRUCKER, 1983). Dentre essas, destacam-se características oligárquicas, normas de comportamento, desejos de expansão burguesa e variadas formas de controle social.

${ }^{6}$ Evidenciam-se, neste contexto, diferentes concepções sobre a díade Virtù-Fortuna (SKINNER, 2002, 88-112).
} 
cosmológicas, políticas, retóricas do período, as quais devem ser estudadas para um melhor entendimento das propostas e das constituições das variadas obras de Machiavelli ${ }^{7}$. A Fortuna, ao atingir a todos e ser perpetuada pelas ações de todos, dissolve tradições e considerações estáveis, associando-se, invariavelmente à ação inexorável do tempo e suas transformações. No desenrolar político das sociedades renascentistas italianas, a descrição de um quadro político desolador, perante as aparências republicanas arquiteta pelos Médici, requer uma oposição à inércia e um desprendimento dos interesses pessoais nas ações civis. Neste contexto, portanto, a Virtù pensada por Cavalcanti opõe-se a uma forma de tirania, sobretudo em face das aparentes decisões coletivas realizadas nas assembleias ${ }^{8}$.

Tais considerações possuem suas raízes em desenvolvimentos intelectuais apresentados desde a Grécia antiga, em que a Fortuna é honrada e temida, responsabilizada pelos acontecimentos e propulsora das ações humanas9. A Tyche transforma o rico em pobre; é generosa e cheia de caprichos; encontra-se em todos os eventos do mundo. Por ser imprevisível, indomável e sem meios de ser entendida racionalmente, apresenta-se como algo maligno a perpetuar as limitações e a miserabilidade humanas. Todavia, por meio da Tyche, mediante suas atividades a promover inevitáveis mudanças, os sucessos das ações humanas são obtidos, ordenações políticas são estabelecidas, impérios são conquistados. Ao não poder ser controlada, ela insere incertezas, mistérios e dúvidas a ponto de conduzir todos os humanos, e.g., atletas, heróis, pescadores, governantes, a refletir sobre suas vitórias e seus fracassos, suas potências e suas limitações. Por um lado, a eficiência nos atos humanos deve ser cultivada; todavia, a Tyche torna os fracos, fortes; reduz os ricos à miséria; fornece dádivas a quem não as pode encontrar por suas próprias forças; retira as possibilidades daqueles que possuem os meios necessários de obter àquilo que desejam. Não há explicação plausível e razoável para suas ações, mas ela não pode ser unicamente responsabilizada pelos acontecimentos, visto não coadunar com a imprudência.

Há, ao longo das inúmeras trocas simbólicas nas eras imperiais helênicas e romanas, asserções sobre a imprevisibilidade e, em decorrência, malignidade da Tyche e da Fortuna; todavia, concomitantemente, existem as posições que realçam os sucessos imperiais e promovem uma avaliação positiva dessas inexoráveis mudanças. Mediante conexões e desconexões no ato receptivo, as concepções da Fortuna no mundo romano também são manifestas em todas as estratificações sociais, associando-se aos sucessos imperiais, mas também realçando suas ambiguidades e ambivalências (POLLIT, 1994, 12-17; BROUCKE, 1994, 33-49; CANTER, 1992, 64-82). Pode-se considerar que as ponderações cristãs, ao proporem a graça e a providência divinas, desarticulam as características do imponderável mediante expressões e realizações

\footnotetext{
7 As heranças antigas, medievais e humanistas não podem ser ignoradas para uma melhor compreensão das ideias e das propostas de Machiavelli. Os diversos meios de interagir com as múltiplas formas destas tradições culturais permitem uma discussão sobre continuidades e descontinuidades, ou ainda, as relações entre originalidade e inspiração, na concepção de uma proposta intelectual (LEFORT, 2012, 3-10). Dentre as variadas tradições propostas nas diversas formas e características presentes nos movimentos humanistas, as relações entre texto, história e ação permitem uma distinção entre uma vida contemplativa e um agente intelectual a perpassar as ordens políticas institucionalizadas. Os trabalhos de Petrarca são exemplos incontestes a respeito da possibilidade de capacitação humana visando ao envolvimento civil mediante considerações morais e artifícios retóricos. A necessidade da ação, desvela uma correlação entre as compreensões sobre a Lei, a Verdade e a Retórica.

${ }^{8}$ Os usos de inúmeros artifícios para a manutenção do poder, dentre os quais a retórica, a força e outras manobras, caracterizaram as “patriche", seja em sua aparente decisão coletiva ou ainda mediante seus traços notórios de dominação política, cabível de ser entendida aos moldes de uma tirania (BIGNOTTO, 1991, 35; 66-74).

${ }^{9}$ Destacam-se algumas imagens nas odes de Píndaro, nas reflexões dos tragediógrafos Ésquilo e Eurípedes, em algumas discussões filosóficas de Platão e Aristóteles, assim também nas fábulas de Esopo. Diante da impossibilidade de uma racionalização precisa, sobretudo diante de um sistema causal adequado, evidenciam-se as imagens pelas quais a Tyche perpassa variados estratos da sociedade helênica antiga (De Assis, 2019, 301-309.)
} 
escatológicas e apocalíticas ${ }^{10}$. Ressaltam, assim, o governo divino e suas inegáveis ações para o bem humano nas articulações do summum bonum ${ }^{11}$. Esta relação entre Providência, Fortuna e desconhecimento humano das ações divinas é destacada por Virgílio em um pedido de explicação de Dante no quinto círculo do Inferno $^{12}$. Se este poeta florentino associa a Fortuna à Intelligenza e à ordem do universo, Bocaccio relacionará a mesma às possibilidades das ações narradas no Decameron ocorrer, embora mantenha a racionalidade e a efetivação da vontade divina (CIOFFARI, 1974, 1-13) Vincenzo Cioffari, "The function of Fortune in Dante, Boccaccio and Machiavelli" Italica 24.1 (1947): 1-13..

Em diálogo com estas tradições, Machiavelli ressalta a instabilidade da condição humana por meio de descrições poéticas e considerações intelectuais a respeito da Fortuna, uma força caprichosa que eleva aos humanos e os destrói, aparentando-se a uma mulher caprichosa amiga dos jovens ${ }^{13}$. Em oposição às implacáveis forças da Fortuna, Machiavelli enfatiza a noção antiga da Virtù em contraposição ao acaso e às determinações exteriores ao humano, requerendo flexibilidade para melhor se adequar às circunstâncias (MANSFIELD, 1998, 49-52). Nota-se, portanto, o modo seletivo em que o autor florentino adentra as incomensuráveis vias destas tradições antigas, medievais e do humanismo cívico italiano. Cicero, por exemplo, em sua obra De Officiis, descreve um bom líder em sua escolha deliberada em evitar a brutalidade e a violência, traçando uma distinção entre vir e as bestas. Reconhecendo esta herança, atestada e revivida pelo humanismo cívico italiano ${ }^{14}$, Machiavelli desvirtua tais imagens ao propor que o governante deve agir como uma besta selvagem em um mundo marcado pelo engano e pela crueldade $^{15}$. Os humanistas, seguindo uma corrente interpretativa ${ }^{16}$, fazem uma associação entre virtus e vis, diferenciando, portanto, qualidades cardeais e força bruta. Por outro lado, Machiavelli insiste que a força é uma condição sine qua non para o exercício do governo, seja em defesa das cidades em batalhas, da Liberdade, ou ainda na conquista e na manutenção do stato $^{17}$.

10 Todavia, as plurais articulações desses conceitos devem ser consideradas em seus contextos particulares, nos quais Providência e Fortuna podem estar amalgamadas, devido às ações benéficas nas quais o humano pode encontrar refúgio, conforto e salvação (POCOCK, 1975, 31-35). Essa diversidade de entendimentos é mais bem exemplificada em algumas passagens de Agostinho e de Boécio, nas quais as adversidades ocasionadas pela Fortuna preparam o humano para realizar o necessário (van EGMOND, 2018, 22-58; BOETHIUS, 1978, II.7-8).

${ }^{11}$ A finitude humana em face à complexidade do cosmos é um tema bíblico recorrente, sobretudo na impossibilidade de uma resposta categórica ao mal, e.g., o caso de Jó. Ao adentrar a convolutas, complicadas e complexas transformações da Fortuna no ambiente helênico e romano, as reflexões patrísticas discutem cultos imperiais, características civis, percepções populares em consonância a considerações teológicas judaicocristãs. A graça, a providência e o amor divinos são motrizes de uma nova concepção, restando à Fortuna, em muitos casos, a subserviência (FRAKES, 1988, 11-29).

${ }^{12}$ “Oh creature scioche, quanta ignoranza è quell ache v'offende! Or vo'che tu ia sentenza ne imbocche. Colui lo cui saver tutto transcende fece li cieli e dié lor chi conduce sí che ogni parte ad ogni parte splende, distribuindo igualmente la luce" (DANTE, Inferno VII, 70-76).

${ }^{13}$ É-nos impossível registrar, e analisar, todas as aparições do termo e de seus derivados no corpus do secretário florentino. Todavia, tais ilações se fazem notar nas obras históricas, nas ponderações sistemáticas e também nas obras ficcionais. A benignidade, a malignidade, os infortúnios e os sucessos, podem ser vistos tanto pela Fortuna, mas também pela Virtù, em atuação na constante flexibilidade humana diante das circunstâncias: una astuzia fortunata.

${ }^{14}$ Verifica-se, portanto, que as virtudes cardeais não se associam apenas aos valores e às tradições cristãs medievais no contexto do humanismo e do renascimento italianos. De fato, o hábito de aconselhar as ações dos príncipes relacionava uma conduta pessoal e pública que visava a exposição das qualidades pessoais dos governantes. Afastavam-se, assim, aos vícios e aos maus comportamentos como condição de se viver na res publica (SKINNNER, 2004, 39-92; 144-146). Tais considerações estão também nas exposições sobre a Providência, a Fortuna e a Virtude nas tradições latinas, em especial nas discussões do humanismo cívico, nas quais se evidenciam maneiras pelas quais as formas proféticas e apocalípticas, herdadas desde os tempos bíblicos, poderiam encontrar ressonâncias seculares significativas nas formas republicanas em solo italiano desde o final do século XV (POCOCK, 1975, 31-48).

${ }^{15}$ Quando Machiavelli afirma "Dovete adunque sapere come sono dua generazione di combattere: l'uno con le leggi, l'altro con la forza: quel primo ̀̀ proprio dello uomo, quel secondo delle bestie: ma, perché el primo molte volte non basta, conviene ricorrere al secondo. Per tanto a uno principe è necessario sapere bene usare la bestia e lo uomo.", deve-se considerar a proposta do uso da astúcia das raposas e da força do leão. Em outras palavras, não há um modo restritivo nas ações dos governantes, na opinião do pensador florentino, mas tanto a força quanto a astúcia devem ser usadas de maneira coerente de acordo com a situação (P. XVIII; BENNER, 2009, 197-201).

${ }^{16} \mathrm{~A}$ diferenciação entre algumas ideias associadas à Escolástica e as novas tendências humanistas propiciou inúmeras correlações decorrentes da via contemplativa e da via activa. Todavia, apesar do desejo de uma obtenção da gloria mundi, tais autores conservam algumas posições éticas e morais herdadas da Cristandade (SKINNNER, 2004, 118-159).

${ }^{17}$ A utilização de mercenários; o reconhecimento da fragilidade dos estados italianos perante as constantes incursões francesas; o treinamento das milícias florentinas; sua opinião sobre profetas desarmados; e o louvor aos grandes homens do passado que se ergueram pela astúcia e pela 
Em contraposição a uma vivência considera sem vigor e incapaz de legitimar leis e estabelecer a ordem, a Virtù é uma iniciativa pessoal a expressar habilidade, força e astúcia contra a aflição, a desordem e as misérias - as quais também são decorrentes da Fortuna. $O$ revigoramento dos ideais cívicos nos reinos italianos opõe-se a usos das tradições pretéritas que não enfatizam a realização presente, a gloria e a ambizione. Nas palavras de Quentinn Skinner, faz-se necessária a "ancient prudence in the face of modern vandalism" ${ }^{18}$. Interpretações relevantes das obras de Machiavelli, invariavelmente sustentam suas avaliações na relação entre Virtù e Fortuna em passagens particulares do autor (MANSFIELD, 1998, 6-15; GILBERT, 1951,5355). Diante da ambivalência e da ambiguidade da ideia de Virtù perante relevantes e variadas tradições, contínuas buscas por clarificação são feitas ao longo desse corpus, associando o termo a outras importantes e centrais reflexões, e.g., desiderio, stato, forza entre outros ${ }^{19}$. A instabilidade política, as forças além do controle humano, a imponderabilidade das ações civis são temas recorrentes nas concepções sobre a Fortuna ${ }^{20}$. Desse modo, reinserir a relevância da paridade entre Fortuna e Virtù em Machiavelli é um passo relevante no combate aos anacronismos, os quais fragilizam "nossa leitura dos textos principais de Maquiavel no lugar de esclarecê-los"21. Ao estudar a díade Virtù-Fortuna no autor, temas primordiais, e.g., força, história, degeneração, corrupção, ambição e glória são ressaltados em todos os assuntos humanos e em suas repercussões políticas. Para tanto, analisar-se-ão os exemplos mais significativos dos fundadores e dos sustentadores da ordem civil, destacados nos textos discursivos do florentino ${ }^{22}$, e..g, Rômulo, Numa, Moisés; Cesare Bórgia; Castruccio Castracani. Assim, ao avaliar as ações da Fortuna, em face das concepções políticas e antropológicas do autor, evidenciam-se possíveis respostas humanas, as quais, se adequadas são vistas como plenas de Virtù. Desse modo, destaca-se a centralidade da díade Virtù-Fortuna no desenvolvimento argumentativo de suas principais obras.

Ao mesmo tempo temida por sua ação devastadora, a Fortuna propicia a Ocasião por meio da qual a Virtù atinge sua excelência na criação e na fundação das ordenações civis

força são alguns bons exemplos (VIROLI, 2002, 99-120; VIVANTI, 2016, 113-117). Evidentemente, conforme visto em seus múltiplos exemplos históricos, a sagacidade da raposa sem esquecer da necessária força do leão merece grande destaque.

${ }^{18}$ No caso da obtenção da glória e do poder pelo Príncipe, a virtù é essencial para mantenere lo stato, pois decorre de suas qualidades pessoais o sucesso de seus empreendimentos. Skinner salienta, ao interpretar tais passagens, que além da conquista e da manutenção do poder, a Virtù é uma condição sem a qual a glória dos grandes homens não poderia ser obtida (SKINNNER, 2004, 144-145). Salienta o autor em sua descrição do contexto histórico nas quais as reflexões de Machiavelli se sustentavam: os principais objetivos do secretário florentino enraizavam-se na restauração, revisão e desenvolvimento dos modos tradicionais em que as commune italianas pensavam o governo livre (161). Acrescenta também que o bene commune e o vivere libero são alguns dos benefícios que o cidadão comum associa à Liberdade e, portanto, o corpo dos cidadãos necessita de uma virtù coletiva que preze pela preservação da vida e da liberdade da commune (163-164).

19 Não há dúvidas que as ilações de Machiavelli estão de acordo com as reflexões de seu tempo, tampouco é possível negar as aplicações e inovações do pensador florentino em seus contextos e por suas intenções particulares (WHITFIELD, 1943, 222-225). No caso do termo gloria, as motivações para as ações humanas, mediante as intenções humanas de satisfação pessoal e social contrapõem-se às virtudes estéreis de uma tradição que não se sustenta nas necessidades inerente aos povos itálicos (RUSSELL, 1977, 588-631). Desta maneira, para um melhor entendimento do termo em seus escritos, faz-se necessário avaliar cada caso no processo de sua argumentação para não confundir o uso da força com violência desproporcional, o stato com tirania, ou o desejo com o vício (SKINNNER, 2004, 139-155).

${ }^{20}$ Nas palavras de Pocock: "Fortune is, first of all, the circumstantial insecurity of political life. Her symbol is the wheel, by which men are raised to power and fame and, then, suddenly cast down by changes they cannot predict or control. It is the engagement in the affairs of the civitas terrena which commits us to the pursuit of power and so to the insecurities of fortuna; but if happenings in the world of power-centered human relationships are of all things the least predictable and those we most desire to predict". (POCOCK, 1975, 38).

${ }^{21}$ Ao analisar diferentes passagens na obra do secretário florentino, o Neewton Bignotto discorre sobre as diferenças posições renascentistas sobre a natureza humana, ponderando que o abandono de um pretenso otimismo sobre as ações humanas, respectivamente sua natureza, decorre justamente da presença da Fortuna na arena política perante os limites da Virtù. Tal negatividade da percepção do humano não quer eliminar a complexidade do problema, porém, visa a ressaltar as ações necessárias sem qualquer qualificação com os predicados morais associados aos discursos a despeito do humano (BIGNOTTO, 2008, 77-100).

${ }^{22} \mathrm{O}$ uso dos exampla romanos na construção retóricas dos discursos, em suas premissas históricas, civis e morais são bastante estudadas, perpassando diversos gêneros escritos e construções materiais nos processos da constituição de identidades culturais e políticas (BELL, 2008; ROLLER, 2018; CHAPLIN, 2000). Machiavelli utiliza-se dessa tradição retórica em variados pontos de sua obra, manifestando artifícios retóricos variados na promoção de sua mensagem (BONADELLA, 1973). 
necessárias para a libertà. O surgimento de Roma e sua decorrente grandeza evidenciam características históricas exemplares em que as ações solitárias de Rômulo e a legislação proposta por Numa indicam como ações individuais extraordinárias são necessárias para a criação de uma ordem e a manutenção da mesma é mais bem articulada pelo consenso obtido pelas necessidades civis, o ardor militar e o ânimo religioso. Os regimes políticos devem estar aptos a se adaptarem aos imperativos das ocasiões, cultivando a Virtù em constantes e variados modos de retornar aos princípios primordiais da organização social estabelecida. Devem-se conjugar as aptidões de Rômulo e de Numa; estar preparado para os tempos de guerra e para os momentos de paz. Assim também é descrito Moisés, pois, ao utilizar uma autoridade não estabelecida por sua própria potência, foi hábil em eliminar a discórdia e as divisões, agindo para salvaguardar o interesse público na promulgação de seus éditos, a ponto de eliminar seus adversários. Exigem-se industria e forza para a instauração e para a manutenção da ordem. Assim, entende Machiavelli que as belas palavras proféticas sem coerções militares possibilitam o surgimento de desordens que conduziram a península itálica à situação de miséria, abandono e escravidão. Desse modo, Cesare Bórgia e Castruccio Castracani são apresentados como idealizações dos governantes que personificaram a Virtù necessária para superar as idiossincrasias da Fortuna. Em ambos, a astúcia e a força são manifestas ao longo de suas jornadas; contudo, no desenrolar de suas carreiras, mesmo os mais aptos não conseguem resistir aos caprichos e desmandos de uma maligna Fortuna que age além dos controles humanos: privaos de conquistar a glória em decorrência de mortes súbitas. Os paralelos entre os dois personagens desvelam um modelo de cidadão com dotes físicos e civis adequados para o exercício do comando, ao demonstrarem audácia, força, astúcia, indústria, prudência, amabilidade na conquista de territórios, na preservação de amigos, na eliminação de inimigos e em todos os outros caminhos para a manutenção do poder e para a promoção das ordens civis.

Rômulo é apresentado junto a Ciro e Moisés em Il Principe, expondo os modos pelos quais a Fortuna propicia a Ocasião na qual sua Virtù alcança excelência na criação e na fundação de Roma ${ }^{23}$. Esses mesmos atos são vistos na exposição da grandeza dessa cidade devido às ordenações implementadas desde a sua origem nos Discorsi: a ação solitária de Rômulo funda um viver civil pela autoridade de suas ações que propiciam as ordenações propostas por Numa ${ }^{24}$. A excelência de Rômulo é atestada pelas ocasiões que cercaram sua vida e suas ações, essas são mais facilmente realizadas por serem atos armados ${ }^{25}$. A origem de Roma é retratada pela mistura dos elementos históricos e do míticos, e..g, Enéas e Rômulo. Evidencia-se que a edificação de uma urbe livre é atribuída a esse último, ao estar relaciona às forças daqueles nascidos no local e não pelas mãos de estrangeiros ${ }^{26}$. As ordenações civis de Rômulo, em conjunto com as legislações de Numa, garantem o sucesso da cidade e seu amplo domínio ao longo do tempo. Desse modo, as ações individuais e coletivas personificam a Virtù necessária para as conquistas e para as ordenações na Roma antiga ${ }^{27}$.

\footnotetext{
${ }^{23} \mathrm{P}$; VI.

${ }^{24}$ D I.1; 9;11;19.

${ }^{25} \mathrm{P}$. VI "E però conviene essere ordinato in modo, che, quando non credono più, si possa fare loro credere per forza. Moisè, Ciro, Teseo e Rom ulo non arebbono possuto fare osservare loro lungamente le loro constituzioni, se fussino stati disarmati".

${ }^{26}$ D. I.1 "Chi esaminerà, adunque, la edificazione di Roma, se si prenderà Enea per suo primo progenitore, sarà di quelle cittadi edificate da' forestieri, se Romolo di quelle edificate dagli uomini natii del luogo; ed in qualunque modo, la vedrà avere principio libero, sanza dependere da alcuno". ${ }^{27}$ D. II.1.
}

ASSIS, Jean Felipe de. A díade virtù-fortuna na fundação e manutenção da ordem em Niccolò Machiavelli. Griot : Revista de Filosofia, Amargosa - BA, v.20, n.2, p.309-331, junho, 2020. 
Dentre os variados tipos de República, a romana caracteriza-se por ter suas leis surgidas paulatinamente devido a eventuais acidentes ${ }^{28}$. A felicidade das cidades que não precisam ser reformadas é grande, pois o caminho para reestabelecer uma boa ordenação é árduo, visto que os humanos não se submetem às inovações, sobretudo àquelas que retiram seus privilégios ${ }^{29}$. Desse modo, não há como impedir a degeneração das formas de regime em seus vícios mais obtusos ${ }^{30}$. No caso particular de Roma, o controle desejado em que as formas de regime possam ser conjuntamente usadas para a preservação da libertà ${ }^{31}$ não ocorreu pela Virtù de um governante: Machiavelli atribui tal ação à Fortuna. A mudança do regime monárquico para o republicano exigia disposições que os reis não poderiam imaginar e estabelecer. Expulsam os reis, sem eliminar a possibilidade de uma autoridade real; ao estabelecerem a magistratura consular, criam os tribunos para acalmar os clamores populares; assim, geriam os tumultos e os conflitos entre as estratificações, meios necessários para a uma República perfeita. As leis que sustentavam o vivere libero romano são obras da Fortuna e da ocasião ${ }^{32}$, as quais demandam ação vigorosa, de indivíduos e da coletividade. Ordenar ou reformar uma República realiza-se mais facilmente por ações individuais, sobretudo diante da necessidade de praticar atos contrários ao senso comum. Nesse sentido, Rômulo deve ser lembrado como aquele que instaura um regime que considera o bem comum, não para ganhos pessoais, mesmo tendo que cometer um homicídio. ${ }^{33}$ Possui em si mesmo a Virtù para as ordenações civis e não carece de uma autoridade divina ${ }^{34}$. Tamanhos foram os efeitos de suas ações que possibilitam as ordenações de Numa, devendo ser imitado por aqueles que ambicionam a manter o poder em todos os tempos ${ }^{35}$, mas também diante das dificuldades em manter os princípios da liberdade republicana ${ }^{36}$. Assim, Rômulo e Numa são exemplos a serem imitados, pois devido às suas ações

\footnotetext{
${ }^{28}$ D.I.2. As Repúblicas possuem diversos princípios, leis e ordenações ao longo da história, mas Machiavelli constata em sua leitura de Tito Lívio que o caso romano exigia constantes reformas e refundações em face aos acontecimentos para assegurar suas bases essenciais. “alcune le hanno avute a caso, ed in più volte e secondo li accidenti, come ebbe Roma".

${ }^{29}$ D I.2. A partir dessa constatação, a necessidade de novas ordenações pode conduzir Repúblicas à ruina, "perché gli assai uomini non si accordano mai ad una legge nuova che riguardi uno nuovo ordine nella città se non è mostro loro da una necessità che bisogni farlo; e non potendo venire questa necessità sanza pericolo, è facil cosa che quella republica rovini, avanti che la si sia condotta a una perfezione d'ordine".

${ }^{30}$ D. I.2 Machiavelli, em aberto diálogo com as formas de regime no pensamento aristotélico, sugere que há três estados (stati) possíveis para a ordenação civil: Principado, Aristocrático (Ottimati) e o Popular. Nada há que impeça a degeneração das formas de regime, os quais possuem curta duração, seja em suas qualidades ou em seus vícios. "perché il Principato facilmente diventa tirannico; gli Ottimati con facilità diventano stato di pochi; il Popolare sanza difficultà in licenzioso si converte. Talmente che, se uno ordinatore di republica ordina in una città uno di quelli tre stati, ve lo ordina per poco tempo; perché nessuno rimedio può farvi, a fare che non sdruccioli nel suo contrario, per la similitudine che ha in questo caso la virtute ed il vizio". Demonstra sua perspectiva em uma genealogia do poder político e da justiça na constante variação desses regimes em suas boas e em suas más atualizações.

${ }^{31}$ D.I.2. Após expor as transformações dos regimes, "E questo è il cerchio nel quale girando tutte le republiche si sono governate e si governano", Machiavelli pondera que nenhuma República retorna às mesmas formas de governo, mas gradativamente perde seu vigor inicial e adquire outros modos de existência. A brevidade dos bons modos e a malignidade das formas pérfidas exigem um comando estável que guarde a libertà, as qualidades específicas e expulse os vícios de cada regime. "Talché, avendo quelli che prudentemente ordinano leggi, conosciuto questo difetto, fuggendo ciascuno di questi modi per sé stesso, ne elessero uno che participasse di tutti, giudicandolo più fermo e più stabile; perché l'uno guarda l'altro, sendo in una medesima città il Principato, gli Ottimati, e il Governo Popolare".

32 D.I.2. A famosa tese de Machiavelli de que os tumulti entre a Plebe e o Senado sustentavam a libertà de Roma e sua República é vista nessa argumentação como um resultado fortuito da ambição dos poderosos e da necessidade das camadas mais populares. A mistura dos regimes idealizada por Machiavelli, portanto, não é o resultado de um humano com Virtù ou da civilità. "E tanto le fu favorevole la fortuna, che, benché si passasse dal governo de' Re e delli Ottimati al Popolo, per quelli medesimi gradi e per quelle medesime cagioni che di sopra si sono discorse, nondimeno non si tolse mai, per dare autorità agli Ottimati, tutta l'autorità alle qualità regie; ne si diminuì l'autorità in tutto agli Ottimati, per darla al Popolo; ma rimanendo mista, fece una republica perfetta: alla quale perfezione venne per la disunione della Plebe e del Senato, come nei dua prossimi seguenti capitoli largamente si dimosterrà".

33 D.I.9. Ao matar seu irmão e consentir em outras mortes, Rômulo perpetua uma ação extraordinária somente mediante sua autoridade pessoal na ordenação civil para o bem comum. Julgar-se-ia aquele que efetiva tais atos pelos seus resultados e não pelos meios de obtenção dos mesmos "Conviene bene, che, accusandolo il fatto, lo effetto lo scusi; e quando sia buono, come quello di Romolo, sempre lo scuseră".

${ }^{34}$ D.I.11.

35 D.I.19.

${ }^{36}$ D. I.49.
}

ASSIS, Jean Felipe de. A díade virtù-fortuna na fundação e manutenção da ordem em Niccolò Machiavelli. Griot : Revista de Filosofia, Amargosa - BA, v.20, n.2, p.309-331, junho, 2020. 
foram assegurados os sucessos de Roma ${ }^{37}$. Ao desejar longa vida para um regime republicano, é mister retornar constantemente aos seus princípios norteadores, sem os quais a degeneração da civilidade e da religiosidade conduzem ao enfraquecimento pessoal e comunitário ${ }^{38}$, sem esquecer-se da necessidade de atos individualizados.

Numa possui uma significante presença no desenvolvimento da argumentação do primeiro livro dos Discorsi, sobretudo devido a sua caracterização como legislador e atuante primordial para a preservação da ordem romana estabelecida. Para tanto, Machiavelli discorre a respeito da atuação sacerdotal para animar a população, estabelecendo e preservando a ordem civil em busca da libertà. As dificuldades encontradas, interna e externamente, exigem constante vigilância e adequações aos perigos presentes. Ao buscar elogiar o paradigma republicano idealizado em suas leituras de Tito Lívio, Machiavelli propõe que a origem da cidade foi livre e sem depender de outros. Ademais, as leis recém-criadas por Rômulo são efetivadas com grande êxito por Numa, a tal ponto que o sucesso posterior de Roma não deve ser visto apenas como decorrente da Fortuna, mas da ação desses personagens na Ocasião apresentada. Nem mesmo suas múltiplas vantagens materiais, e.g., fertilidade, posição no mar, vitórias militares, ou o tamanho do domínio, puderam corromper a Virtù dessa cidade ${ }^{39}$. Desenvolvem-se, no primeiro livro dos Discorsi pela exposição de Numa, as possibilidades de uma Virtù civil para se cultivar a libertà mediante a presença do ânimo religioso, a necessidade de uma ação individual e a força para a manutenção da Ordem diante da corrupção dos costumes $^{40}$. Há, assim, um louvor às ações de Rômulo e Numa nas ordenações e legislações, ao mesmo tempo em que é apresentada uma censura contra àqueles que buscam preservar somente a belicosidade do primeiro ou apenas os meios pacíficos do segundo.

Ao discorrer sobre a religião dos romanos, Machiavelli infere que as leis promulgadas por Numa possuem inspiração divina, confirmadas pelo grandioso sucesso dessa cidade ${ }^{41}$. Ao encontrar um povo ferrosíssimo, obtem paz e obediência civil para a manutenção da sociedade (civilità) por meio dos ritos religiosos ${ }^{42}$. O fervor civil, nutrido pela crença religiosa, propicia o amor à pátria e atesta a implementação das leis. A religião propicia o ânimo militar, promovendo concórdia na população, a qual não é facilmente obtida quando apenas a autoridade individual é utilizada. A Virtù de Numa, portanto, promulga uma legislação e uma obediência às instituições civis que sustentam todo o desenrolar histórico da cidade de Roma ${ }^{43}$.

\footnotetext{
${ }^{37}$ D. III.1 Ao mostrar a degeneração da ordem civil em Roma, Machiavelli conclui que o retorno aos princípios fundadores, nas seitas religiosas e nas repúblicas são as bases de sustentação dessas possuírem maior longevidade. "Hanno ancora $i$ regni bisogno di rinnovarsi, e ridurre le leggi di quegli verso i suoi principii"; "Conchiudesi, pertanto, non essere cosa più necessaria in uno vivere comune, o setta o regno o republica che sia, che rendergli quella riputazione ch'egli aveva ne' principii suoi"

38 D. III,1

${ }^{39}$ D. I. 1. "vedrà ancora, come di sotto si dirà, a quante necessitadi le leggi fatte da Romolo, Numa, e gli altri, la costringessono; talmente che la fertilità del sito, la commodità del mare, le spesse vittorie, la grandezza dello imperio, non la potero per molti secoli corrompere, e la mantennero piena di tanta virtù, di quanta mai fusse alcun'altra città o republica ornata".

${ }^{40}$ Dsicussão bastante pertinente sobre as formas de regime políticos, no contexto da chamada "Questão Maquiavélica". A Virtù individual na criação de uma ordem civil deve ser seguida de uma virtuosidade republicana para a sua preservação. JohnBernard. Why Machiavelli Matters: $A$ Guide to Citizenship in a Democracy. London: Praeger, 2009, 59-76. As mudanças nos regimes podem ser vistas como correções para a perda da Virtù individual e coletiva. Harvey Mansfield. Machiavelli's New Modes and Orders: A study of the Discourses on Livy. Chicago: University of chicago Press, 2001, 85-90.

${ }^{41}$ DI.11. As ordenações de Rômulo não seriam suficientes para explicar o sucesso posterior de Roma. Desse modo, os céus inspiram o senado em sua eleição de Numa. "giudicando $i$ cieli che gli ordini di Romolo non bastassero a tanto imperio, inspirarono nel petto del Senato romano di eleggere Numa Pompilio per successore a Romolo, acciocché quelle cose che da lui fossero state lasciate indietro, fossero da Numa ordinate".

${ }^{42}$ D. I.11. "Il quale, trovando uno popolo ferocissimo, e volendolo ridurre nelle obedienze civili con le arti della pace, si volse alla religione, come cosa al tutto necessaria a volere mantenere una civiltà".

${ }^{43}$ D. I.11. Maiores detalhes são vistos nas discussões a respeito da Religião no pensamento de Machiavelli. Todavia, a personificação da Virtù civil em Numa é destacada pelas ordenações civis e a bem-aventurança de Roma, pois das boas ordenações são geradas boas fortunas e dessas redundam sucessos nas atividades civis. "Considerato adunque tutto, conchiudo che la religione introdotta da Numa fu intra le prime cagioni della felicità di quella città: perché quella causò buoni ordini; $i$ buoni ordini fanno buona fortuna; e dalla buona fortuna nacquero i felici successi delle imprese. E come la osservanza del culto divino è cagione della grandezza delle republiche, così il dispregio di quello è cagione della rovina d'esse".
} 
Contudo, apenas uma dependência da Virtù dos antecessores não permite a subsistência de uma urbe a longo prazo, visto que os frutos das boas ordens não perduram para a eternidade ${ }^{44}$. Devese, portanto, conjugar as aptidões de Rômulo e Numa em todas as gerações ${ }^{45}$ : a arte da guerra e a arte da paz. Decerto, o princípio da liberdade, defendido na fundação de Roma, encontrava constantes obstáculos, exigindo sempre novas ações, novas criações e novas instituições ${ }^{46}$.

Machiavelli destaca a figura de Moisés em Il Principe e nos Discorsi como um governante de Virtù na utilização de uma autoridade proveniente dos ritos religiosos, mas sem esquecer a organização social e o uso das armas. Dessa maneira, o famoso personagem judaico-cristão é contraposto a profetas desarmados, e.g., Savonarola, os quais não possuem possibilidade de serem bem-sucedidos, mas também àqueles que ignoram ou não compreendem os modos pelos quais os ritos religiosos são importantes para a coesão militar e civil.

Ao discutir os modos pelos quais as cidades são fundadas e mantidas, Moisés e Enéas são comparados devido às imigrações e conquistas militares de $\operatorname{ambos}^{47}$ : na exposição de Machavelli, o personagem bíblico conquista e instala seu povo em localidades com estruturas políticas já existentes ${ }^{48}$, enquanto o herói de Virgílio edifica uma nova urb. Expondo outras características das variadas possibilidades para as cidades estabelecidas, realça a importância da liberdade dos humanos, as leis promulgadas e a natureza da região escolhida para sua localização ${ }^{49}$. Se inicialmente há um silêncio aos modos pelos quais as leis devam ser promulgadas ou reformadas na comparação entre esses personagens, posteriormente, os Discorsi aludem para a necessidade de uma ação individual, a pensar mais no interesse público do que nos benefícios pessoais, mesmo com o uso da violência - Coloca Moisés, portanto, em paralelo com Rômulo ${ }^{50}$. Se o indivíduo funda e reforma às ordenações civis, a coletividade é o melhor meio de salvaguardar essas $^{51}$. Ademais, ao relatar a criação dos cônsules romanos, delineia que as ações em prol do coletivo são sustentadas pela autoridade dada pela população aos governantes e fundadores, apontando os exemplos de Moisés, Licurgo e Sólon ${ }^{52}$. Não desenvolve seu argumento e as

\footnotetext{
${ }^{44}$ D. I. 19. "Donde si può notare che uno successore, non di tanta virtù quanto il primo, può mantenere uno stato per la virtù di colui che lo ha retto innanzi, e si può godere le sue fatiche: ma s'egli avviene o che sia di lunga vita, o che dopo lui non surga un altro che ripigli la virtù di quel primo, è necessitato quel regno a rovinare".

${ }^{45}$ D. I.19. Em espaço oportuno, na exposição da personificação da Virtù em Rômulo, verifica-se o conselho dado a todos os governantes em ter uma predileção às ações de Rômulo, pois serão capazes de conservar seu stato ao empunharem prudência e armas, em todos os tempos, contra os caprichos da Fortuna.

46 D. I.49. Exemplifica Machiavelli que os Censores foram criados para conter a degeneração das ordenações civis, mas são exemplos significativos da corrupção e da gradativa perda de liberdade. Assim, há sempre novos desafios a serem realizados na defesa da civilità: "nondimeno sempre nel maneggiare quella città si scoprivono nuove necessità, ed era necessario creare nuovi ordini".

${ }^{47}$ D. I.1.

${ }^{48}$ Retorna essa compreensão ao discutir os motivos pelos quais as populações abandonam suas pátrias e invadem territórios alheios. D. II.8. Ambição, guerras, fome, conflitos são alguns dos exemplos pelos quais as conquistas militares e a imposição de novas ordens civis são observadas. Desse modo, as ações de Moisés são associadas aos povos que invadiram o império romano, fundando reinos, mudando leis e transformando costumes. "e la necessità nasce o dalla fame, o da una guerra ed oppressione che ne' paesi propri è loro fatta: talché e' son constretti cercare nuove terre. E questi tali, o $e^{\prime}$ sono gran numero; ed allora con violenza entrano ne' paesi d'altrui, ammazzano gli abitatori, posseggono $i$ loro beni, fanno uno nuovo regno, mutano il nome della provincia: come fece Moisè, e quelli popoli che occuparono lo Imperio romano".

${ }^{49}$ D I.1. Deseja argumentar que a cidade de Roma foi fundada por origens livres e independentes, seja ao se considerar Enéas ou Romulo. Ao listar alguns exemplos históricos, e.g., Egito, Alexandre e outros, Machiavelli pondera que o vigor civil e militar deve ser cultivado pelos habitantes, inclusive pelo uso de leis, da religião e da força.

${ }^{50}$ D.I. 9 Na argumentação exposta, lembrando o assassinato feito por Rômulo, o uso da autoridade conquistada na esfera pública é individual e não pode ser reprovada quando usada, mesmo que violentamente, para o bem comum. "Però, uno prudente ordinatore d'una republica, e che abbia questo animo, di volere giovare non a sé ma al bene comune, non alla sua propria successione ma alla comune patria, debbe ingegnarsi di avere l'autorità, solo; né mai uno ingegno savio riprenderà alcuno di alcuna azione straordinaria, che, per ordinare un regno o constituire una republica, usasse".

${ }^{51}$ D. I.9. Continuando suas analogias com a fundação de Roma, Machiavelli descreve que a criação do Senado demonstra a intenção de uma criação para o bem coletivo, sem interesses pessoais, para que as ordens estabelecidas sejam mais bem administradas. "E che Romolo fusse di quelli che nella morte del fratello e del compagno meritasse scusa, e che quello che fece, fusse per il bene comune, e non per ambizione propria, lo dimostra lo avere quello, subito ordinato uno Senato, con il quale si consigliasse, e secondo la opinione del quale deliberasse".

52 D. I.9. "Potrebbesi dare in sostentamento delle cose soprascritte infiniti esempli; come Moises, Licurgo, Solone, ed altri fondatori di regni e di republiche, $e^{\prime}$ quali poterono, per aversi attribuito un'autorità, formare leggi a proposito del bene comune".
}

ASSIS, Jean Felipe de. A díade virtù-fortuna na fundação e manutenção da ordem em Niccolò Machiavelli. Griot : Revista de Filosofia, Amargosa - BA, v.20, n.2, p.309-331, junho, 2020. 
características desses líderes em detalhes por considerar os mesmos de conhecimento geral ${ }^{53}$, mas relata como Ágis assassina os líderes opositores que o impedem de restabelecer a ordem desejada em Esparta, pois esses evitavam que ele obtivesse a autoridade por suas ambições pessoais ${ }^{54}$.

Novamente, encontram-se as justificativas para essa interpretação das ações de Moisés em passagens posteriores dos Discorsi. Ao discorrer a respeito de um cidadão que deseja criar algo bom com sua autoridade, deve eliminar a inveja daqueles que desejam o poder e ordenar militarmente à cidade perante seus inimigos externos ${ }^{55}$. Ao ler as ações de Camilo em Tito Lívio, Machiavelli pondera sobre os meios utilizados para a organização dos exércitos, para o fornecimento de armas e comida, assim também para o aparelhamento dos negócios públicos. Nesse último caso, nomea seus mais próximos colegas e partidários, afastando a inveja e honrando suas ações com altas magistraturas. Assim, a Virtù de Camilo dispersa a inveja, por sua sabedoria e bondade, sendo extremamente útil para a pátria ${ }^{56}$. Perigos iminentes, assim também a violenta e pública morte de seus inimigos, são outros meios de superar esse malefício que impede as boas ações dos cidadãos e corrompem as ordens civis ${ }^{57}$. Nesse contexto, apresenta "uma interpretação sensata" de Moisés, pois esse é forçado a matar inúmeros opositores, os quais cheio de inveja, impossibilitavam a efetivação de seus desígnios e de suas leis ${ }^{58}$. Atitude impossível de ser seguida por Savonarola, pois não detinha autoridade, e também por Piero Soderini, que acreditava que sua bondade, a sua Fortuna, os benefícios dados dispersariam a inveja e as consequentes lutas pelo poder sem qualquer tumulto, violência e escândalo ${ }^{59}$. Esses dois exemplos sucumbiram por não terem a mesma atitude vista em Moisés, visto que não seja possível esperar que os humanos mudem com o tempo, pois a bondade não é suficiente, a Fortuna é volátil e a maldade indomável ${ }^{60}$.

A famosa reprovação feita ao Frei Girolamo Savonarola em Il Principe compartilha esse mesmo contexto argumentativo. Ao discorrer sobre os principados novos adquiridos por armas próprias e Virtù, a imitação dos caminhos bem-sucedidos por outros, adaptados à situação, deve ser considerada para que ao menos certo "odor" desses bons desígnios antigos sejam sentidos no presente. Moisés é apresentado como um príncipe novo que obteve sua posição por Virtù pessoal, não por Fortuna - é visto em paralelo a Ciro, Rômulo e Teseu ${ }^{61}$. Primeiramente, Machiavelli escusa racionalizar sobre Moisés, pois esse seria um mero executor das ordens divinas ${ }^{62}$. Todavia, mostra como as ações de Ciro e outros que fundaram reinos não são discrepantes às de Moisés, embora não possuísse um preceptor divino ${ }^{63}$. Ao estudar a vida desses fundadores, avalia-se que a Fortuna apenas propicia a ocasião e a efetivação material para a

\footnotetext{
${ }^{53}$ D. I. 9. " ma li voglio lasciare indietro, come cosa nota".

${ }^{54}$ D. I.9.

55 D. III, 30.

${ }^{56}$ D. III. 30 "in modo furono quegli Tribuni, in quelli tempi, per la salute della patria, disposti a comandare ed a ubbidire. Notasi per questo testo, quello che faccia uno uomo buono e savio, e di quanto bene sia cagione, e quanto utile e' possa fare alla sua patria, quando, mediante la sua bontà e virtù, egli ha spenta la invidia".

${ }^{57}$ D. III. 30 .

${ }^{58}$ D. III. 30. "E chi legge la Bibbia sensatamente, vedrà Moisè essere stato forzato, a volere che le sue leggi e che $i$ suoi ordini andassero innanzi, ad ammazzare infiniti uomini, i quali, non mossi da altro che dalla invidia, si opponevano a' disegni suoi".

${ }^{59}$ D. III. 30 .

${ }^{60}$ D. III. 30. "il tempo non si può aspettare, la bontà non basta, la fortuna varia, e la malignità non truova dono che la plachi. Tanto che l'uno e l'altro di questi due rovinarono, e la rovina loro fu causata da non avere saputo o potuto vincere questa invidia".

${ }^{61}$ P VI." Ma, per venire a quelli che per propria virtù e non per fortuna sono diventati principi, dico che li più eccellenti sono Moisè, Ciro, Romulo, Teseo e simili",

${ }^{62}$ P. VI. "E benché di Moisè non si debba ragionare, sendo suto uno mero esecutore delle cose che li erano ordinate da Dio". Ressalta que Moisés deveria ser admirado por ter a dádiva de poder falar com Deus.

${ }^{63}$ P. VI. "Ma consideriamo Ciro e li altri che hanno acquistato o fondato regni: li troverrete tutti mirabili; e se si considerranno le azioni et ordini loro particulari, parranno non discrepanti da quelli di Moisè, che ebbe sì gran precettore".
} 
forma desejada e estipulada pela Virtù pessoal desses iniciadores ${ }^{64}$. As adversidades decorrentes da escravidão dos judeus no Egito são condições necessárias, propiciadas pela Fortuna na gestão da Ocasião, para que o povo obedeça a Moisés com o objetivo de sair da servidão ${ }^{65}$. Assim também são vistas as circunstâncias das vidas e das ações Rômulo, Ciro e Teseu: as adversidades são materializações da Ocasião mediante as quais a Virtù pessoal é manifesta no fortalecimento do coletivo ${ }^{66}$. As dificuldades das conquistas e da manutenção das ordens, decorrentes dos desejos humanos e da inconstância dos povos, exigem Virtù e Forza, pois a persuasão demanda ordenação civil e meios pelos quais a crença da coletividade seja mantida. Desse modo, para o estabelecimento da obediência civil e para a superação dos inimigos - internos e externos - fazse necessário o uso da força: os profetas armados, vencem; os desarmados são arruinados ${ }^{67}$. Em sua exortação final aos cabeças da península itálica para superar os governos estrangeiros em seus territórios, Machiavelli aconselha ao seu destinatário a observar essas mesmas ações listadas em comparação com as ações necessária na situação dessas comune. A Itália está dilacerada, reduzida, escravizada, sem liderança e carente da Virtù de Moisés, da grandeza do ânimo de Ciro e da excelência de Teseu ${ }^{68}$. Embora existam pequenos momentos de respiro - spiraculo-, essas cidades encontram-se sufocadas à espera da Virtù a reanimar os antigos valores que não estão mortos no coração dos humanos ${ }^{69}$.

Personagem histórico e ficcional ${ }^{70}$ no corpus de Machiavelli, Cesare Bórgia, o duque Valentino, é, ao mesmo tempo, um paradigma a ser seguido por sua ascensão e um exemplo a ser evitado devido a sua queda. Em Il Principe ${ }^{71}$, encontra-se o maior número de citações, mas há menções importantes nos Discorsi e em outros escritos ${ }^{72}$. A descrição dos métodos usados na morte de Vitellozo Vitelli, Oliverotto da Fermo e o Gravina Orsini ${ }^{73}$ é um elemento textual bastante conhecido e importante para a avaliação de Machiavelli a respeito desse duque. Reúne em si qualidades paralelas ao relato biográfico de Castruccio Castracani, buscando a todo instante autossuficiência para depender apenas de sua Virtù e não do sucesso de outros. Embora tenha sucumbido por uma doença inesperada, seus graduais avanços na Romanha concedem a esse duque fama, prestígio e reputação.

Em Dell'arte della guerra, embora Fabrizio prefira não tratar dos personagens contemporâneos ao período do diálogo, pela dificuldade de falar de si e por não saber o que falar

\footnotetext{
${ }^{64}$ Machiavelli articula Fortuna, Ocasião, ação, ânimo e Virtù, mediante as causas materiais e formais dos novos principados: A Fortuna apresenta a ocasião; a vontade pessoal fornece a forma; o ânimo é mantido pela Virtù e pela Ocasião; sem a força individual a Ocasião proposta teria sido nula. Nas palavras do autor: "Et esaminando le azioni e vita loro, non si vede che quelli avessino altro dalla fortuna che la occasione; la quale dette loro materia a potere introdurvi drento quella forma parse loro; e sanza quella occasione la virtù dello animo loro si sarebbe spenta, e sanza quella virtù la occasione sarebbe venuta invano." P. VI.

${ }^{65}$ P VI. "Era dunque necessario a Moisè trovare el populo d'Isdrael, in Egitto, stiavo et oppresso dalli Egizii, acciò che quelli, per uscire di servitù, si disponessino a seguirlo."

${ }^{66}$ P. VI. A Ocasião torna o humano afortunado e a Virtù, caminho para a excelência, transforma a desfortuna para o bem da pátria. "Queste occasioni, per tanto, feciono questi uomini felici, e la eccellente virtù loro fece quella occasione esser conosciuta; donde la loro patria ne fu nobilitata e diventò felicissima".

${ }^{67}$ P. VI. Em todos os desafios para a manutenção, diante da inconstância dos povos e dos princípios da ambição humana, o uso da forza é necessária: "Di qui nacque che tutt'i profeti armati vinsono, e li disarmati ruinorono". Quando não mais obedecem e creem pelo ânimo, devem ser forçados a isso: "E però conviene essere ordinato in modo, che, quando non credono più, si possa fare loro credere per forza".

${ }^{68} \mathrm{P} . \mathrm{XXVI}$.

${ }^{69}$ P. XXVI. Uma paráfrase ao dito de Petrarca que Machiavelli utiliza-se ao final da obra para chamar a casa dos Medici à ação: “Virtù contro a furore / Prenderà l'arme, e fia el combatter corto; / Ché l'antico valore / Nell'italici cor non è ancor morto".

70 Além dos textos discursivos, Cesare Bórgia é mencionado por Fabrizio como um exemplo contemporâneo ao dialogar sobre a guerra, mas também é mencionado nos Decennali. Assim, reúne em si elementos históricos e literários na composição de exemplum a ser seguido pelos príncipes.

${ }^{71}$ P. III; VII; XIII; XVI; XX

${ }^{72}$ AG VII; D II. 24 ; I. 38. III. 27; Dec 258; 343

${ }^{73}$ Descrizione del modo tenuto dal Duca Valentino nello ammazzare Vitellozzo Vitelli, Oliverotto da Fermo, il Signor Pagolo e il duca di Gravina Orsini (DDV)
}

ASSIS, Jean Felipe de. A díade virtù-fortuna na fundação e manutenção da ordem em Niccolò Machiavelli. Griot : Revista de Filosofia, Amargosa - BA, v.20, n.2, p.309-331, junho, 2020. 
dos outros ${ }^{74}$, abre exceções para retratar as ações de Cesare Bórgia. No primeiro exemplo descreve o cerco a Forlì em que a fortaleza de Catarina Sforza é conquistada pela má engenhosidade da construção e pela fraqueza de ânimo dos encarregados de sua defesa ${ }^{75}$. Efetiva-se um evidente paralelo com algumas argumentações em Il Principe e nos Discorsi em que as fortificações não devem ser escolhidas em detrimento de outros meios de estabilidade civil e militar ${ }^{76}$. Ademais, atesta a engenhosidade no combate em Urbino, enganando seus adversários, pois ao esconder a direção dos seus ataques conseguia ocupar em um dia cidades que demandariam muito trabalho e despesas ${ }^{77}$. $\mathrm{O}$ crescente poder político e notória reputação são atestados na submissão de suas vontades ao cruzar o território florentino à força, desvelando a fraqueza do regime político dessa cidade e a materialização da Virtù pessoal desse duque. As formas republicanas débeis hesitam em suas decisões e agem mais pela necessidade do que pela deliberação. Desse modo, a indecisão fornece uma resposta no afã dos acontecimentos e não pela sabedoria $^{78}$. Assim, relata a indecisão de Florença diante do pedido do duque Valentino, que deseja cruzar a cidade ao retorna de uma negociação com Bolonha. $O$ impasse resultou que o duque fizesse seu percurso à força, demonstrando sua potência e, ao mesmo tempo, a fraqueza de Florença que se via coberta de vergonha ${ }^{79}$.

Ao discorrer sobre as dificuldades de novas ordens em um Principado misto, Machiavelli expõe como Luís XII, rei da França, propiciou o crescimento do poder temporal da Igreja e não auxiliou àqueles que anteriormente haviam feito acordos nas terras itálicas ${ }^{80}$. Considera o autor florentino que o monarca francês cometeu uma série de erros ${ }^{81}$, os quais podem associar-se a tentativas de evitar conflitos bélicos e honrar palavras dadas ao papa. Pondera Machiavelli que nunca se deve deixar prosperar uma desordem civil para afastar a guerra, pois apenas postergase o inevitável com altos custos para a civilità; além de seus famosos ditos a respeito da manutenção da palavra e da integridade ${ }^{82}$. Cesare Bórgia, em contrapartida, está sempre apto a

${ }^{74}$ AG VII. "Io ragiono male volentieri delle cose successe de' nostri tempi, perché di me e de' miei mi sarebbe carico a ragionare; d'altri non saprei che mi dire"

${ }^{75}$ AG. VII. Fabrizio atesta a Virtù e a coragem de Catarina, mesmo diante da derrota em uma batalha inglória contra as forças do duque Valentino auxiliado pelos franceses.

${ }^{76} \mathrm{P}$ XX. Argumenta, assim, que o povo de Forlì aliou-se aos estrangeiros e seria mais vantajoso à condessa não ser odiada por seu próprio povo do que as fortalezas materiais. Nas palavras do autor "Per tanto allora e prima sarebbe suto più sicuro a lei non essere odiata dal populo, che avere le fortezze". Entende, portanto, que as fortalezas podem ser mais nocivas do que úteis para a manutenção da ordem, visto que um exército forte propicia maiores benefícios. D. II.24. Exemplifica essa posição pelo retorno do duque Urbino que, ao recuperar seus territórios, manda destruir suas fortalezas, pois as considerava perigosas nas mãos dos inimigos, preferindo cultivar a afeição do povo e manter um exército permanente. Pelo respeito a Urbino, o povo tampouco queria fortalezas. "come dipoi, per uno accidente nato, vi ritornò, fece rovinare tutte le fortezze che erano in quella provincia, giudicandole dannose. Perché, sendo quello amato dagli uomini, per rispetto di loro non le voleva; e, per conto de' nimici, vedeva non le potere difendere, avendo quelle bisogno d'uno esercito in campagna, che le difendesse".

${ }^{77}$ AG. VII. "trovandosi a Nocera con le sue genti, sotto colore di andare a' danni di Camerino si volse verso lo stato d'Urbino, ed occupò uno stato in uno giorno e sanza alcuna fatica, il quale un altro con assai tempo e spesa non arebbe appena occupato".

${ }^{78}$ D. I. 38. Mostra exemplos das indecisões de Florença que evidenciam sua fraqueza frente ao reino francês, ao duque Valentino e às outras cidades italianas. Em todos esses casos, Machiavelli assevera que as dúvidas nesses contextos apenas são superadas por atos violentos, o que caracterizaria uma ordem civil débil, sempre em suspeição e sem uma ação efetiva. "E cosi, per tornare a proposito, le republiche inresolute non pigliono mai partiti buoni, se non per forza, perché la debolezza loro non le lascia mai deliberare dove è alcuno dubbio; e se quel dubbio non è cancellato da una violenza che le sospinga, stanno sempre mai sospese".

${ }^{79}$ D. I. 38. O duque estava altamente armado e essa cidade desarmada, seria diplomaticamente mais aceitável a Florença consentir a passagem do que ter essa feita à força.

${ }^{80}$ P. III.

${ }^{81}$ P.III. Lista cinco erros cometidos nos assuntos da península: aniquilou os menos potentes; aumentou o poder de uma potente Igreja; implementou um governador estrangeiro; não decidiu habitar nessas terras; não implementou colônias. "Aveva, dunque, Luigi fatto questi cinque errori: spenti e' minori potenti; accresciuto in Italia potenzia a uno potente, messo in quella uno forestiere potentissimo, non venuto ad abitarvi non vi messo colonie".

${ }^{82}$ No primeiro caso, assevera, nas mesmas passagens, a importância de manter a ordem civil, mesmo na iminência de um conflito indesejado: " $E$ se alcuno dicesse: el re Luigi cedé ad Alessandro la Romagna et a Spagna el Regno per fuggire una guerra; respondo, con le ragioni dette di sopra, che non si debbe mai lasciare seguire uno disordine per fuggire una guerra, perché la non si fugge, ma si differisce a tuo disavvantaggio". P. III. A manutenção da fidelidade e integridade, sobretudo no que tange a promessas, é visto como uma fraqueza diante de tantos exemplos históricos em que a astúcia e a industria são mais eficazes. P. XVIII. Deve-se aparentar e não necessariamente ter as qualidades morais desejadas pelo senso comum.

ASSIS, Jean Felipe de. A díade virtù-fortuna na fundação e manutenção da ordem em Niccolò Machiavelli. Griot : Revista de Filosofia, Amargosa - BA, v.20, n.2, p.309-331, junho, 2020. 
usar da força e da dissimulação, buscando a todo instante criar meios de atualizar sua potência e sua Virtù.

No contexto dos Principados adquiridos pela Fortuna ou pelas armas de outros, o autor de Il Principe alude a dois exemplos que considera estar na memória coletiva de seu tempo: Francesco Sforza e Cesare Borgia. O primeiro, com grande Virtù tornou-se duque de Milão, todavia, as muitas atividades para a conquistas resultam em pouco reforço para a manutenção ${ }^{83}$. O Valentino, por sua vez, adquire seu domínio e o perde em decorrência da Fortuna do Pai, Papa Alexandre VI ${ }^{84}$. Embora Cesare Borgia pudesse agir conforme o esperado, pleno de Virtù, uma tremenda e maligna Fortuna o impediu de obter o êxito desejado $^{85}$. Na leitura de Machiavelli, Alexandre VI perturbou as ordens e desordenou as cidades italianas pela reputação do rei francês, adquirindo um reino na Romanha para o seu filho ${ }^{86}$. Esse viu-se impossibilitado de expandir pela fraqueza de suas armas e pelo desejo do rei estrangeiro. O Valentino não desejava depender das armas e da Fortuna alheias ${ }^{87}$, tornando os adeptos de seus inimigos seus correligionários, fornecendo chefias militares e de governo ${ }^{88}$. Aguardou a ocasião adequada, usando de simulação e dissimulação, para exterminar seus opositores, promovendo o bem-estar das regiões conquistadas - destaca-se o que deva ser digno de imitação ${ }^{89}$. Após reunir-se com o rei Luis, Cesare Bórgia desejava atacar Bolonha para assegurar seu território na Romanha. Alguns de seus seguidores, dentre os quais os Vitegli e os Orsini, temiam que ele se tornasse muito poderoso e os eliminasse para se tornar senhor único desses domínios ${ }^{90}$. Preocupavam-se com a grandeza, o ânimo e o apetite do duque ${ }^{91}$. As conjurações foram conhecidas e todos aqueles que estavam descontentes com o Valentino armavam-se para o combater. Esse encontrou proteção em Florença e aguardava os reforços da França. Nesse meio tempo, dissimulava que gostaria de permanecer apenas com as honras públicas, mas o domínio deixaria para os seus antigos subordinados, enquanto aumentava suas providências para o confronto ${ }^{92}$. Persuadia a seus inimigos com acordos, tratados de paz e benesses ao mesmo tempo que, em silêncio, pagava a todos os seus soldados para estarem aptos e prontos para a guerra. Enganava aos conjurados com astúcia e sagacidade ${ }^{93}$, fornecendo a impressão que

${ }^{83}$ P. VII. "Francesco, per li debiti mezzi e con una gran virtù, di privato diventò duca di Milano; e quello che con mille affanni aveva acquistato, con poca fatica mantenne".

${ }^{84}$ P. VII, "Dall'altra parte Cesare Borgia, chiamato dal vulgo duca Valentino, acquistò lo stato con la fortuna del padre, e con quella lo perdê"

85 P. VII, Cesare Borgia é um exemplo para os príncipes novos, visto que suas ações sistematizam os melhores preceitos desejados. Todavia, a Fortuna o impede de realizar o seu desejo: "li quali non iudico superfluo discorrere, perché io non saprei quali precetti mi dare migliori a uno principe nuovo, che lo esemplo delle azioni sua: e se li ordini sua non li profittorono, non fu sua colpa, perché nacque da una estraordinaria et estrema malignità di fortuna".

${ }^{86}$ P. XI. A grandeza da Igreja e suas ações políticas possuem em Alexandre VI uma atualização das possíveis repercussões políticas da inserção eclesiástica nos assuntos terrenos mediante a expansão de seus domínios e a utilização da força.

${ }^{87}$ P. VII. "Onde che il duca deliberò non dependere più dalle arme e fortuna di altri". Desejava um domínio independente dos sucessos das comune $\mathrm{e}$ do reino francês na península itálica.

${ }^{88}$ P. VII. Transforma os cidadãos leais aos outros governos na Romanha em adeptos de sua causa provendo quantidades materiais e honrarias sociais de acordo com o desejo de cada um. Nas palavras de Machiavelli: "E, la prima cosa, indeboli le parti Orsine e Colonnese in Roma; perché tutti li aderenti loro che fussino gentili uomini, se li guadagnò, facendoli sua gentili uomini e dando loro grandi provisioni; et onorolli, secondo le loro qualità, di condotte e di governi"'.

${ }^{89}$ P. VII. Machiavelli, portanto, destaca que o exercício da Virtù pessoal, mediante o sucesso militar, a simulação, a dissimulação e o exterminar dos inimigos são dignos de nota, pois consegue aniquilar seus adversários e trazer para si a população da Romanha. "E, perché questa parte è degna di notizia e da essere imitata da altri, non la voglio lasciare indrieto"

${ }^{90} \mathrm{DDV}$ "parse loro come il Duca diventava troppo potente, e che fusse da temere, che occupata Bologna non cercasse di spegnerli, per rimanere solo in sull'armi in Italia"

${ }^{91} \mathrm{DDV}$ Era visto como um perigo para todos aqueles que possuíam algum interesse na região: “si disputò della grandezza del Duca e dell'animo suo, e come egli era necessario frenare lo appetito suo"

92 DDV. Descreve, portanto, os meios pelos quais a simulação de Cesare Borgia garantia-lhe o tempo necessário para estar fortalecido militarmente. "essendo grandissimo simulatore, non mancò di alcuno ufficio a fare intendere loro, che eglino avevano mosso l'armi contro a colui, che ciò che aveva acquistato voleva che fusse loro, e come gli bastava avere il titolo di principe, ma che voleva che il principato fusse loro".

${ }^{9} \mathrm{DDV}$ Aceitava uma reunião com os conjurados, sem dar mostras que já havia reunido em torno de si um forte exército: "con tutte quelle astuzie e sagacità potette, persuase a Vitelli e agli Orsini che lo aspettassino in Sinigaglia".

ASSIS, Jean Felipe de. A díade virtù-fortuna na fundação e manutenção da ordem em Niccolò Machiavelli. Griot : Revista de Filosofia, Amargosa - BA, v.20, n.2, p.309-331, junho, 2020. 
estaria disposto a aceitar sua atual condição. Todavia, ao possuir maior poder bélico, domina seus opositores e os executa.

O duque Valentino, portanto, é um exemplo de Virtù em comparação com a fraqueza dos demais senhores da região, pois esses semeavam a desunião devido à permissividade, latrocínios, brigas e insolências ${ }^{94}$. Ao discutir os caminhos possíveis da piedade e da crueldade, Machiavelli atesta que um príncipe deve ser tido por piedoso e não por cruel. Todavia, a exemplo de Rômulo que comete um assassinato para fundar a cidade de Roma, Cesare Bórgia pode ser visto como cruel por alguns, muito embora tais ações tenham reconciliado a Romanha. Conclui o autor, portanto, que tais ordenações são mais pias do que aquelas existentes entre o povo florentino que permitiam grandes desuniões e facções ${ }^{95}$. A pacificação requereu medidas violentas, purgadas publicamente para ganhar a comoção popular, um espetáculo bastante conhecido que gerou impacto, estupefação, satisfação e terror nos habitantes locais ${ }^{96}$. As divisões nas cidades possuem três meios de resolução, de acordo com Machiavelli: exterminar as pessoas, remover da cidade, ou obrigar as partes a fazerem as pazes com a coação de não se ofenderem ${ }^{97}$. Esse último é menos eficaz, mais danoso e possui pouca utilidade, visto que os meios para as intensas querelas existem diariamente; o primeiro é o mais seguro, mas uma República débil mal consegue executar os exílios, com grandes custos em sua atuação. A debilidade humana para a ação civil nutre-se da fraqueza educacional devido ao pouco conhecimento das coisas antigas ${ }^{98}$. Assim, os agentes civis preferem confiar em estrangeiros e em fortalezas, em manter as cidades divididas.

Tornava-se cada dia mais poderoso, eliminava seus inimigos, precavia-se da morte de Alexandre VI, avançava até a Toscana ao ponto de estar próximo de depender apenas de sua própria potência e Virtù ${ }^{9}$. Machiavelli, ao discorrer a respeito das milícias, se essas deveriam ser auxiliares, mistas ou próprias, indica ao leitor, novamente, o crescente desejo de autossuficiência, visto que ele abandona o uso das tropas auxiliares francesas e o uso dos mercenários, e.g., os Orsini e os Vitelli ${ }^{100}$. Machiavelli utiliza-se das ações do duque Valentino para asseverar que ele garantiu maior respeito ao ser inteiramente dono de suas armas ${ }^{101}$.

94 P. VII. A região carecia de um bom e ordenado governo que a pacificasse, todavia, nenhum de seus senhores havia sido capaz de realizar tal coisa. A Romanha “comandata da signori impotenti, li quali più presto avevano spogliato e' loro sudditi che corretti, e dato loro materia di disunione, non di unione, tanto che quella provincia era tutta piena di latrocinii, di brighe e di ogni altra ragione di insolenzia, iudicò fussi necessario, a volerla ridurre pacifica e obediente al braccio regio, darli buon governo".

95 P. XVII. Para evitar a acunha de cruel, os florentinos evitaram destruir Pistóia, gerando mais inimizades e maiores divisões. Conclui Machiavelli que um príncipe não deve se importar com a fama de cruel, mas explorá-la para os fins de ordenar uma boa civilità para o bem da coletividade. "Debbe, per tanto, uno principe non si curare della infamia di crudele, per tenere e' sudditi sua uniti et in fede; perché, con pochissimi esempli sarà più pietoso che quelli e' quali, per troppa pietà, lasciono seguire é disordini, di che ne nasca occisioni o rapine: perché queste sogliono offendere una universalità intera, e quelle esecuzioni che vengono dal principe offendono uno particulare". Esse episódio é também lembrado pelas dificuldades de apaziguar os ânimos, realçando como o domínio de Florença em Pistóia, mostra a utilidade e o perigo dos exílios. D III. 27. Esse mecanismo propicia inúmeras divisões e incessantes conflitos.

${ }^{96}$ P. VII. Buscava mostrar, nas palavras de Machiavelli, que os possíveis excessos não eram resultantes de seu desejo, mas foram ações feitas por aqueles que ele havia delegado. Ao sacrificar um de seus oficiais, purgava possíveis rancores. "La ferocità del quale spettaculo fece quelli populi in uno tempo rimanere satisfatti e stupidi". Cita o mesmo episódio no capítulo seguinte, no caso de Oliverotto da Fermo e suas ações para obter o poder em sua cidade.

${ }^{97}$ D III. 27. "o ammazzargli, come feciono costoro; o rimuovergli della città; o fare loro fare pace insieme, sotto oblighi di non si offendere".

${ }_{98}$ D III.27 “Ma la debolezza de' presenti uomini, causata dalla debole educazione loro e dalla poca notizia delle cose, fa che si giudicano $i$ giudicii antichi, parte inumani, parte impossibili".

${ }^{99}$ P. VII. Os paralelos são muitos com o relato biográfico de Castruccio Castracani, sobretudo a mensagem a Pagolo no qual esse deveria depender apenas de si mesmo e de sua industria, devido ao ódio gerado e a impossibilidade de receber ajuda de outros. Encaminhava-se por força e por reputação à autossuficiência. "si acquistava tante forze e tanta reputazione, che per sé stesso si sarebbe retto, e non sarebbe più dependuto dalla fortuna e forze di altri, ma dalla potenzia e virtù sua".

${ }^{100}$ P. XIII, A utilização das tropas estrangeiras não parecia seguro e confiável; os mercenários são perigosos para a reputação e infiéis; sua reputação aumenta, atingindo ao ápice quando possuía suas próprias armas. "E puossi facilmente vedere che differenzia è infra l'una e l'altra di queste arme, considerato che differenzia fu dalla reputazione del duca, quando aveva Franzesi soli e quando aveva li Orsini e Vitelli, a quando rimase con li soldati sua e sopr'a sé stesso e sempre si troverrà accresciuta".

${ }^{101}$ P. XIII. "né mai fu stimato assai, se non quando ciascuno vidde che lui era intero possessore delle sue arme"

ASSIS, Jean Felipe de. A díade virtù-fortuna na fundação e manutenção da ordem em Niccolò Machiavelli. Griot : Revista de Filosofia, Amargosa - BA, v.20, n.2, p.309-331, junho, 2020. 
Todavia, a morte do pai, a saúde debilitada, os grandes exércitos em sua volta e a eleição de Júlio II o impediram de consolidar seu domínio ${ }^{102}$. Ainda assim, conclui Machiavelli que Cesare Bórgia é um exemplo ideal para um príncipe novo, listando as ações desse: precaver-se dos inimigos; ganhar para si amigos; vencer pela força ou pela fraude; fazer-se amado e temido pela população; ser seguido e respeitado pelos soldados; aniquilar àqueles que possam ameaçar; renovar com novos modos as ordens antigas; ser severo e grato, magnânimo e liberal; exterminar as milícias infiéis e criar novas; cultivar amizade de reis e príncipes para o seu benefício e para a redução dos malefícios ${ }^{103}$.

A centralidade da díade Virtù-Fortuna no relato histórico proposto sobre a vida de Castruccio Castracani é evidenciada pelas descrições da fraqueza política das comune itálicas, pelo baixo nascimento do biografado juntamente aos eventos para a sua formação humana e civil, pelos modos de vida e de atuação social em paralelo com os exampla romanos, mas também pela sua surpreende morte quando seus intentos de dominar a Toscana aparentavam estar tão próximos. Machiavelli atesta a fama e a força de Castruccio Castracani nas guerras entre as potências itálicas, recordando como os florentinos se entregaram sem reservas ao poder de Roberto, rei de Nápoles, por buscarem proteção diante da iminente derrota para esse comandante ${ }^{104}$. Ademais, pondera que logo após a morte desse, Florença mostra enorme coragem para atacar o duque de Milão, ainda que tenha sido derrotada em seus próprios territórios ${ }^{105}$. Tal status de Castracani é resultante das constantes batalhas travadas pelo controle da região da Toscana, essas que remontam aos confrontos entre os guelfos e os gibelinos, assim também às variadas facções espalhadas por toda a península itálica, perpassando os poderes imperiais e papais ${ }^{106}$. Desse modo, as guerras entre Florença e Lucca, comandadas por Castruccio Castracani, um jovem, inflamado e feroz ${ }^{107}$ que liderava alguns gibelinos da Toscana, rendem reconhecimento, reputação e fama a esse condottiero ${ }^{108}$. A divisão da cidade de Florença resulta em derrotas vergonhosas e acordos escusos, vãs tentativas de obter o desejado pelos exilados e pelas camadas da população excluídas das decisões centrais ${ }^{109}$. Crescia o domínio e o prestígio de Castracani a ponto de Florença pensar ser necessária uma guerra frontal, terminada em derrota devido às deslealdades e às ambições de seu comandante que desejava ser aclamado Príncipe ${ }^{110}$. Os prejuízos políticos e econômicos foram enormes, pois,

${ }^{102}$ P VII. Destacam-se as injúrias antigas feitas ao novo pontífice, as quais não foram esquecidas. Acredita Machiavelli que ele deveria ter buscado com todas as forças a eleição de um papa espanhol ou francês. Assim, "E chi crede che ne' personaggi grandi e' benefizii nuovi faccino dimenticare le iniurie vecchie, s'inganna. Errò, adunque, el duca in questa elezione; e fu cagione dell'ultima ruina sua".

${ }^{103}$ P. VII. "Chi, adunque, iudica necessario nel suo principato nuovo assicurarsi de' nimici, guadagnarsi delli amici, vincere o per forza o per fraude, farsi amare e temere da' populi, seguire e reverire da' soldati, spegnere quelli che ti possono o debbono offendere, innovare con nuovi modi li ordini antichi, essere severo e grato, magnanimo e liberale, spegnere la milizia infidele, creare della nuova, mantenere l'amicizie de' re e de' principi in modo che ti abbino o a beneficare con grazia o offendere con respetto, non può trovare e' più freschi esempli che le azioni di costui". Novamente, o relato da vida de Castruccio Castracani enumera qualidades similares, com exemplos históricos escolhidos para a promoção da mensagem de Machiavelli.

104 D. II. 9.

105 D. II. 12.

106 IF. I. $26 ; 28$.

${ }^{107}$ IF II 26 "Castruccio Castracani, di cittadino di Lucca, ne divenne signore, e perché era giovane, ardito e feroce, e nelle sue imprese fortunato, in brevissimo tempo principe de' Ghibellini di Toscana divenne".

${ }^{108}$ IF II. 26. Diferente das análises feitas em seu relato histórico e biográfico sobre esse comandante, nesse trecho das Histórias de Florença, Machiavelli expressa que a indecisão do grupo dos governantes propiciou a Castracani refugiar-se em Lucca em seus primeiros embates com essa cidade.

${ }^{109}$ IF II 27. O auxílio dos exilados às tropas de Castruccio Castrcani e as constantes derrotas para Lucca geram revoltas na universalità dos habitantes de Florença.

${ }^{110}$ IF. 29. Acreditava Ramondo di Cardona que os florentinos confiavam sua libertà a pessoas não capacitadas, e.g., o rei de Nápoles e os legados papais. Assim, embora não possuísse autoridade, julgava que seus feitos militares poderiam o conduzir ao principado: "pensava, se conducessi quelli in qualche necessità, che facilmente potrebbe accadere che lo facessino principe. Né mancava di ricordarlo spesso; e chiedeva di avere quella autorità nella città, che gli avevano negli eserciti data, altrimenti mostrava di non potere avere quella ubbidienza che ad uno capitano era necessaria; e perché $i$ Fiorentini non gliene consentivono, egli andava perdendo tempo, e Castruccio lo acquistava". 
além dos eventuais saques, Castracani fazia incursões pelos limites da cidade ${ }^{111}$. Se Florença conseguira integrar Pistóia a seus domínios por acordos, Castracani sitiou a cidade com tamanha Virtù e ostinazione que os florentinos não conseguiam o retirar pela forza, tampouco pela industria $^{112}$. Tais acontecimentos marcam profundamente a concepção política e militar florentina, seja alterando as formas de suas magistraturas ${ }^{113}$, seja nos modos de concepção sobre as divisões internas das facções e suas ambições pelo controle da cidade ${ }^{114}$, ou ainda nas concepções diplomáticas com as outras comune italianas ${ }^{115}$. Nota-se, contudo, que as imagens de Catruccio Castracanni são díspares entre as passagens supracitadas e o relato históricobiográfico proposto por Machiavelli. Nessas, ele é descrito como un vile cittadino lucchese e tiranno; enquanto que naquelas, sua Virtù é louvada em face aos vitupérios da Fortuna.

Destaca Machiavelli que a Fortuna desvela sua força ao mundo ao mostrar que não há prudência que possa tornar algum humano grande ${ }^{116}$. A vida de Castruccio Castracani demonstra esse preceito, por ser de baixo nascimento, não ter nenhuma aflição sobre as mudanças dos tempos e, ainda assim, pelas ações da Fortuna e também pela aquisição de grandes sucessos ser um grande exemplo para os seus contemporâneos ${ }^{117}$. O infante é acolhido por uma família abastada, a exemplo de Moisés, abandonado e cuidado como filho pela piedade alheia $^{118}$. Amadurece como um cidadão modelo, em dotes físicos e civis, mostrando uma variedade de aptidões: destreza na espada; montaria; costumes; modéstia; boa fala; amabilidade $^{119}$, prudência; coragem e popularidade ${ }^{120}$. A exemplo de Cesare Bórgia rejeita uma carreira clerical por ter uma preferência pelas armas $^{121}$. A popularidade e o poder de Castruccio

\footnotetext{
${ }^{111}$ IF II. 29 “I danni che Castruccio fece, dopo la vittoria, a' Fiorentini, di prede, prigioni, rovine e arsioni, non si potrebbono narrare; perché, senza avere alcuna gente allo incontro, più mesi dove é volle cavalcò e corse; e a' Fiorentini, dopo tanta rotta, fu assai il salvare la città".

112 IF II. 30 .

${ }^{113}$ IF II. 30. Descreve-se como a indecisão dos comandantes e o desenrolar dos acontecimentos propiciaram uma nova ordenação civil em Florença.
}

${ }^{114}$ IF III.11 As disputas entre as facções no interior das cidades redundam no aumento da desunião e, consequentemente, no enfraquecimento civil e militar. Desse modo, as urbes desunidas são alvos fáceis para seus inimigos: “Non vi ricordate voi, che quando l'è stata disunita, Castruccio, un vile cittadino lucchese, l'ha battuta? un Duca di Atene, privato condottiere vostro, l'ha subiugata? Ma quando la è stata unita, non l'ha potuta superare uno Arcivescovo di Milano e uno Papa; $i$ quali, dopo tanti anni di guerra, sono rimasi con vergogna. Perché volete voi adunque che le vostre discordie quella città, nella pace, faccino serva, la quale tanti nimici potenti hanno, nella guerra, lasciata libera?"

115 IF IV.19. Lucca é vista amistosamente, a menos quando estava sob regimes tirânicos: "E che nelle memorie delle cose nostre non si troverrà mai Lucca libera avere offeso Firenze ma se chi l'aveva fatta serva, come già Castruccio e ora costui, l'aveva offesa non si poteva imputare la colpa a lei, ma al tiranno. E se al tiranno si potesse fare guerra sanza farla a' cittadini, gli dispiacerebbe meno; ma perché questo non poteva essere, non poteva anche consentire che una cittadinanza amica fusse spogliata de' beni suoi."

${ }^{116} \mathrm{CC}$ I. "volendo la fortuna dimostrare al mondo di essere quella che faccia gli uomini grandi, e non la prudenza, comincia a dimostrare le sue forze in tempo che la prudenza non ci possa avere alcuna parte, anzi da lei si abbi a ricognoscere il tutto"

${ }_{117}$ CC II. Apesar de não possuir um nascimento nobre, devido à sua virtù e à Fortuna é de grande exemplo "La quale mi è parso ridurre alla memoria delli uomini, parendomi avere trovato in essa molte cose, e quanto alla virtù e quanto alla fortuna, di grandissimo esemplo"

${ }^{118} \mathrm{CC}$ IV "Tale che essa, parte maravigliata, parte sbigottita, ripiena di compassione e di stupore, lo ricolse e, portatolo a casa e lavatolo e rinvoltolo in panni bianchi come si costuma, lo presentò, alla tornata in casa, a messer Antonio. Il quale, udendo el caso e vedendo il fanciullo, non meno si riempié di maraviglia e di pietade che si fusse ripiena la donna, e consigliatisi intra loro quale partito dovessero pigliare, deliberorono allevarlo, sendo esso prete e quella non avendo figliuoli. Presa adunque in casa una nutrice, con quello amore che se loro figliuolo fusse, lo nutrirono; e avendolo fatto battezzare, per il nome di Castruccio loro padre lo nominor

${ }^{119}$ CC VI. Converte-se em um cidadão modelo, nas palavras do biógrafo e historiador, são reconhecidas aptidões em um brevíssimo período de tempo:"è cosa straordinaria a pensare in quanto brevissimo tempo ei diventò pieno di tutte quelle virtù e costumi che in uno vero gentile uomo si richieggono." Nesse contexto, lista as qualidades supradestacadas, a ponto de não apenas os amigos e familiares, mas toda a cidade de Lucca amar Castruccio Castracani: "In prima ei si fece uno eccellente cavalcatore, perché ogni ferocissimo cavallo con somma destrezza maneggiava: e nelle giostre e ne' torniamenti, ancora che giovinetto, era più che alcuno altro riguardevole; tanto che in ogni azione, o forte o destra, non trovava uomo che lo superasse. A che si aggiugnevano i costumi, dove si vedeva una modestia inestimabile; perché mai non se gli vedeva fare atto o sentivasegli dire parola che dispiacesse; ed era riverente ai maggiori, modesto cogli equali e cogli inferiori piacevole. Le quali cose lo facevano non solamente da tutta la famiglia de' Guinigi, ma da tutta la città di Lucca, amare".

${ }^{120}$ CC VIII. A fama e a honra de Castruccio Castracani cresciam nas regiões do norte da península itálica, especialmente devido à sua sapiência, coragem e prudência. "Nella quale espedizione Castruccio dette tanti saggi di sé di prudenza e di animo, che niuno che in quella impresa si trovassi ne acquistò grazia appresso di qualunque, quanta ne riportò egli, e non solo el nome suo in Pavia, ma in tutta la Lombardia diventò grande e onorato"

${ }^{121}$ A crise vocacional, segundo o relato de Machiavelli nutrida pelo desejo de seu pai adotivo e as ambições militares de Castruccio Castracani, é testemunhada por Francesco Guinigi, que o faz se transferir de cônego a condottiere devido aos desejos do jovem biografado: "Passato pertanto Castruccio di casa messer Antonio Castracani calonaco in casa messer Francesco Guinigi condottiere" CC VI. 
Castracani cresciam rapidamente, a ponto de gerar inveja e acusações de tirania, sobretudo após a morte de Francesco Guinigi e sua efetivação como tutor de Pagolo, o filho do falecido ${ }^{122}$.

Machiavelli descreve com detalhes a sagacidade política e a eficiência bélica de Castruccio Castracani, especialmente diante das alianças firmadas com outros governantes das comune itálicas, mas também diante das constantes batalhas entre o reino Francês, o território de Nápoles, o Império e a Igreja. Desse modo, o biografado é um exemplo de Virtù nas condições mais adversas, em batalhas físicas ou em negociações públicas. Há inegáveis paralelos com as famosas argumentações expressas em Il Principe e nos Discorsi, a partir das quais Castracani pode ser visto como um modelo histórico a ser seguido de acordo com as interpretações propostas por Machiavelli (BONDANELLA, 1972, 302-314). Desde o baixo nascimento até a repentina morte de Castruccio Castracani a díade Virtù-Fortuna apresenta-se conjugada nos campos de batalha, nos acordos políticos e nos estabelecimentos de ordens civis nas comune da Toscana. As descrições de Machiavelli enfatizam constantes adversidades e os meios pelos quais o personagem histórico supera-as, emulando em muitos momentos posições intelectuais defendidas ao longo do corpus de Machiavelli: a Fortuna assenhora-se dos assuntos humanos e necessita ser combatida ${ }^{123}$; a utilização da forza não é suficiente sem a indústria enraizada na Virtù individual de humanos específicos ${ }^{124}$; no caminho da obtenção do poder e em seu processo de manutenção, invejas pessoais e traições são inseparáveis no exercício do comando civil ${ }^{125}$; fazse necessário aparentar misericórdia e ser implacável contra seus inimigos, replicando a fúria no campo de batalha nos modos de ordenação civil ${ }^{126}$; tanto o indivíduo quanto a cidade possuem somente a si para a defesa da libertà, os humanos, as outras cidades italianas, os reinos estrangeiros, a Igreja e o Império não são confiáveis e não podem fornecer a ajuda necessária no tempo devido ${ }^{127}$. Desse modo, em uma constante e feroz luta contra a Fortuna, a Virtù de Castruccio Castracani é física e retórica, por reunir em torno de si amigos, ser terrível contra os inimigos, justo com seus súditos e ser apto a se adaptar política e militarmente às circunstâncias ${ }^{128}$. Desse modo, o personagem emula a personificação de um exemplum ao melhor estilo da retórica histórica e literária da Roma Antiga.

Estando sob suspeitas diante dos olhares dos poderosos de Lucca, observa as brigas internas e externas de sua cidade. Alia-se a Uguccione, e eles promovem uma batalha no interior e no exterior da cidade simultaneamente, visto que o governante de Pisa forçava uma entrada e Castracani chamava o povo às armas ${ }^{129}$. Acreditava Florença que o partido gibelino havia conquistado muita autoridade na Toscana atacou Lucca. Durante a batalha, Uguccione é acometido de uma doença que o impede de estar na frente de batalha, recaindo tal responsabilidade a Castracani. Esse condottiere, cheio de astúcia, retarda o conflito imediato, aparentando medo aos inimigos, ao mesmo tempo em que anima a seus soldados ${ }^{130}$. Por sua vez,

\footnotetext{
${ }^{122}$ CC X. "Morto pertanto messer Francesco Guinigi, e rimaso Castruccio governatore e tutore di Pagolo, accrebbe tanto in reputazione e in potenzia, che quella grazia che soleva avere in Lucca si converti parte in invidia; talmente che molti, come uomo sospettoso e che avessi l'animo tirannico, lo calunniavano"

${ }^{123}$ CC I; XXXII;

${ }^{124}$ CC VII; VIII; XX; XXII-XXXVI.

${ }^{125}$ CC XIV; XVIII

${ }^{126}$ CC XVIII -XIX.

${ }^{127}$ CC XXXII.

128 CC XXXIV

${ }^{129} \mathrm{CC}$ X. Machiavelli, mesclando o estilo de biógrafo, historiador e pensador político, constanta que enorme dano foi causado à cidade de Lucca diante de um novo governo estabelecido, sobretudo devido ao exilio de seus cidadãos: “e lo Stato della città si riformò secondo che a Uguccione piacque; con grandissimo danno di quella, perché si trova che più di cento famiglie furono cacciate allora di Lucca".

${ }^{130}$ CC XXII. O Aparente temor gera insolência dos florentinos no campo de batalha. "Il che Castruccio cognobbe, e attese per alcuni giorni ad accrescere in loro questa opinione, mostrando di temere, non lasciando uscire alcuno delle munizioni del campo; e dall'altra parte i Guelfi, quanto più vedevano questo timore, tanto più diventavano insolenti, e ciascuno giorno, ordinati alla zuffa, si presentavano allo esercito di Castruccio".
} 
os florentinos criam que seus inimigos estavam sem comando, devido à ausência de Uguccione $^{131}$. Em sua espera, Castracani induziu uma falsa confiança nos soldados inimigos e pode vencer a batalha com um ajuste tático do posicionamento das tropas, eliminando qualquer reação ${ }^{132}$.

A fama de Castracani é enorme devido ao sucesso de suas batalhas, gerando tamanha inveja que a vitória parecia não ter dado o comando, mas o retirado esse de Uguccione ${ }^{133}$. Deve o biografado sobreviver a intrigas políticas e tentativas de assassinatos. Castracani fornece guarida a um assassino de um nobre estimado pelo povo de Lucca, propiciando a Uguccione uma justificativa para a sua prisão e seu assassinato. Pede a seu filho, alocado na cidade, que convidasse Castracani para uma ceia com a finalidade de o prender e o matar. Neri retarda a pena máxima, ao temer a reação popular, exige a confirmação do pai. Após sair de Pisa para realizar a tarefa com quatrocentos cavaleiros, criticando o atraso e a covardia do filho, recebe a notícia que os habitantes de Pisa pegaram em armas, matando os membros de sua família que permaneceram na cidade. Temendo perder Lucca também, Uguccione direciona-se rapidamente à cidade impossibilitado de conter as falas desrespeitosas à autoridade estabelecida (parlare sanza rispetto), as revoltas (tumulti) e a subsequente libertação de Castracani. Diante da fuga de Uguccione, Castracani transforma-se em capitão e príncipe, estando em alta estima com a população de Lucca ${ }^{134}$.

Ao assumir o governo da cidade, Castracani buscava alianças com o império em amistosas recepções com Frederico da Baviera, por meio do qual o controle de Pisa lhe foi garantido $^{135}$. Desse modo, com a reputação conquistada em Lucca e nos campos de batalha, juntamente à aliança com o imperador e os exilados de outras comune itálicas, Castracani desejava assenhorar-se de toda a Toscana ${ }^{136}$. Em meio às batalhas pela conquista da região, Castracani retornou a Lucca para resolver motins que desejavam a sua expulsão. A família Poggio, julgando não ser remunerada segundo os méritos de ter feito Castracani reconhecido e príncipe $^{137}$, inicia uma série de acordos com outras famílias, matando o tenente que administrava a cidade. Stefano di Poggio, visa a conter a escalada de violência e a ser o mediador entre seus desejos e Castracani. Com as armas depostas, Castracani encontra sua cidade pacificada, e promete mostrar sua clemência e liberalidade (clemenza e liberalità): reúne a todos e mata-os ${ }^{138}$. Estabelece uma trégua com Florença e decide assegurar seu poder em Lucca,

\footnotetext{
${ }^{131}$ CC XII "Ma sendo Uguccione aggravato nel male, si ritirò per curarsi a Montecarlo, e lasciò a Castruccio la cura dello esercito. La qual cosa fu cagione della rovina de' Guelfi; perché quegli presono animo, parendo loro che lo esercito inimico fussi rimaso sanza capitano".

${ }_{132}$ CC XXII. Ao conhecer os ajustes feitos no campo de batalha, o condottiere pode animar seus soldados ao mostrar as fraquezas e os meios pelos quais a vitória seria assegurada. "Il quale, parendoli avere dato loro assai animo, e cognosciuto l'ordine loro, deliberò fare la giornata con quegli; e prima con le parole fermò l'animo de' suoi soldati, e mostrò loro la vittoria certa quando volessino ubbidire agli ordini suoi". Os soldados inimigos não possuem o vigor físico de manter a batalha devido ao posicionamente proposto por Castracani e resolvem fugir: "e cosi venivano le più gagliarde genti di Castruccio a combattere con le più debole degli inimici, e le più gagliarde loro si posavano, sanza potere offendere quelli avieno allo incontro, o dare alcuno aiuto alli suoi. Tale che, sanza molta difficultà, $e^{\prime}$ nimici dall'uno e l'altro corno si missono in volta; e quegli di mezzo ancora, vedendosi nudati da' fianchi de' suoi, sanza avere potuto mostrare alcuna loro virtù, si fuggirono". CC XXIII.

${ }^{133}$ CC XXIII. "a Uguccione entrò tanta gelosia e sospetto dello stato suo, che non mai pensava se non come lo potessi spegnere, parendogli che quella vittoria gli avessi non dato ma tolto lo imperio".

${ }^{134}$ CC XV. "Ma Castrucio, di prigioniero diventato come principe di Lucca, operò, con gli amici suoi e con el favore fresco del popolo, in modo che fu fatto capitano delle loro gente per uno anno".

135 CG XVI.

${ }^{136}$ CC XXVII. Destaca-se, contudo, a resistência de Florença a esse domínio. Desse modo, os partidários dos exilidos prometem a Castracani o domínio de suas terras caso sejam vitoriosos no campo de batalha. "Tornatosene pertanto Federigo nella Magna, e lasciato uno governatore a Roma, tutti e' Ghibellini toscani e lombardi, che seguivano le parti dello imperadore, si rifuggirono a Castruccio, e ciascuno gli prometteva lo imperio della sua patria, quando per suo mezzo vi rientrasse; intra quali furono Matteo Guidi, Nardo Scolari, Lapo Uberti, Gerozzo Nardi e Piero Buonaccorsi, tutti ghibellini e fuora usciti fiorentini".

${ }^{137}$ CG XVIII. "Era, in quella città, la famiglia di Poggio potente per avere fatto non solamente grande Castruccio ma principe; e non le parendo essere remunerata secondo $i$ suoi meriti, convenne con altre famiglie di Lucca di ribellare la città e cacciarne Castruccio".

138 Episódio bastante parecido com a descrição feita por Machiavelli sobre os modos pelos quais Cesare Bórgia eliminou a conjuração dos Vitelli, Orsini e outros associados.
}

ASSIS, Jean Felipe de. A díade virtù-fortuna na fundação e manutenção da ordem em Niccolò Machiavelli. Griot : Revista de Filosofia, Amargosa - BA, v.20, n.2, p.309-331, junho, 2020. 
eliminando a seus inimigos e àqueles que pudessem pensar em ter o principado nas mãos: confiscos, mortes e exílios são feitos ${ }^{139}$.

Fortifica-se militarmente com os bens de seus inimigos e busca constantemente crescer seu domínio. Para tanto, engendra o duplo assassinato dos lideres de Pistóia e submete o povo dessa cidade à obediência por sua grande Virtù: não apenas pela trama, mas por promessas e perdões de débitos antigos ${ }^{140}$. O povo de Pistóia aquieta-se pela maestria de Castracani. Sua fama é tamanha que é chamado a apaziguar Roma, ausente do comando papal visto que João XXII estava preso em Avignon. Apenas sua presença, assim também o envio de trigo oriundo de Lucca e a punição dos líderes opositores, promoveu o restabelecimento da ordem sem qualquer derramar de sangue desnecessário. Tais ações fornecem grandes honras a Castracani, inclusive ser elevado a senador romano ${ }^{141}$. Devido às suas ausências de Pistóia, os florentinos julgavam ser possível conquistar a cidade com a ajuda de alguns exilados dessa. Ao invadirem, matam e expulsam os magistrados designados por Castracani. Buscam ainda antecipar os caminhos pelos quais o condottiere retornaria da Romanha. Todavia, ciente que tinha um exército numericamente inferior, Castracani refugia-se no castelo de Serravale, uma posição estratégica que possibilitaria sua vitória ${ }^{142}$. Em posse do castelo, confusão e desordem eram espalhadas nas fileiras da cavalaria e da infantaria florentinas por estarem suprimidos entre um desfiladeiro e a artilharia oriunda da fortaleza. Nesse sentido, destaca-se que Castracani utilizava-se habilmente da forza e da Virtù, ao contrário desses inimigos, os quais, incapacitados de resistir, fugiam ${ }^{143}$. Libera cavaleiros e infantes para destroçarem furiosamente seus inimigos, dentre os quais muitos nobres. Pistóia expulsa os partidários dos florentinos, guelfos, aceitando a submissão a Castracani - celebrada com jogos e moedas satirizando os florentinos ${ }^{144}$.

Florença não é totalmente saqueada pelo auxílio enviado pelo rei Roberto de Nápoles e pela necessidade de Castracani conter a revolta de Benedicto Lanfrachi em Pisa ${ }^{145}$. Esse, não admitindo o domínio de Lucca, decide pela conjuração que acaba com sua morte e de seus familiares. Diante de constantes traições e brigas em Pistóia e Pisa, Castracani estava ciente que não poderia contar com a fidelidade dessas cidades e, portanto, buscava constantemente consolidar seu poder por industria e forza ${ }^{146}$. Por outro lado, com a chegado do príncipe Carlos de Nápoles, Florença armou-se em um grande exército para atacar Pisa - por acreditarem ser suscetível a revoltas e influenciar diretamente às decisões em Pistóia ${ }^{147}$. Perante tamanha adversidade, Machiavelli ressalta a crença de Castracani de que a Fortuna havia lhe conferido a

\footnotetext{
${ }^{139}$ CC XIX. Cria, por experiência, não poder confiar em nenhum desses "né perdonò ad alcuno, privandogli della patria e della roba, e, quegli che poteva avere nelle mani, della vita, affermando di avere conosciuto per esperienza niuno di quegli potergli essere fedele".

${ }^{140}$ CC XX“e tratta la Signoria di palagio, costrinse Castruccio il popolo a dargli obedienza, faccendo a quello molte rimessioni di debiti vecchi e molte offerte; e cosi fece a tutto el contado, il quale era corso in buona parte a vedere il nuovo principe; tale che ognuno, ripieno di speranza, mosso in buona parte dalle virtù sue, si quietò".

${ }^{141}$ CC XXI. Ao receber o cargo, Castracani veste-se com inscrições escatológicas: a realização de ser àquilo que Deus quer - com a frase na frente: "Egli è quel che Dio vuole" - e a esperança que pode ser aquilo que Deus desejar - com a frase nas costas: "E' sarà quel che Dio vorrà".

${ }^{142}$ CC XXIII Destacam-se as posições da batalha, mas também o ânimo de seus soldados: "In questo luogo aveva disegnato Castruccio affrontarsi con gli inimici, sì perché le sue poche gente avessero vantaggio, sì per non iscoprire é nimici prima che in su la zuffa, dubitando che $i$ suoi, veggendo la moltitudine di quegli, non isbigottissino".

${ }^{143} \mathrm{CC}$ XXIV "pure si fece testa per qualcuno di loro, ma, disceso il romore per il resto del campo de' Fiorentini, si riempié di confusione ogni cosa. I cavagli erono oppressi dai fanti, i fanti dai cavagli e dai carriaggi; i capi non potevono per la strettezza del luogo andare né innanzi né indietro, di modo che niuno sapeva in tanta confusione quello si potesse o dovesse fare. Intanto e' cavagli, che erono alle mani con le fanterie nimiche, erano ammazzati e guasti sanza potere difendersi, perché la malignità del sito non gli lasciava; pure più per forza che per virtù resistevono, perché, avendo dai fianchi $i$ monti, di dietro gli amici e dinanzi gli inimici, non restava loro alcuna via aperta alla fuga".

${ }^{144}$ CC XXVII. Além da submissão de Pistóia, Machiavelli descreve que Castracani aproxima-se de Florença e provoca os derrotados em meio a festejos e festas: “dove stette molti giorni a dividere la preda e a fare festa della vittoria avuta, faccendo in dispregio de' Fiorentini battere monete, correre palii a cavagli, a uomini e a meretrici". Visava também invadir sorrateiramente a cidade, mas seus planos foram descobertos.

145 CC XXVIII

${ }^{146}$ CC XXIX "E parendogli avere Pistoia e Pisa poco fedeli, con industria e forza attendeva ad assicurarsene".

${ }^{147}$ CC XXX.
}

ASSIS, Jean Felipe de. A díade virtù-fortuna na fundação e manutenção da ordem em Niccolò Machiavelli. Griot : Revista de Filosofia, Amargosa - BA, v.20, n.2, p.309-331, junho, 2020. 
oportunidade de dominar todo o território da Toscana ${ }^{148}$. Novamente, o condottiere mostra sua maestria: separa o exército inimigo de suas provisões, deixando apenas como opção de batalha atravessar o rio Arno ou lutarem para conquistar um castelo. Ao cruzarem o rio, os soldados florentinos estão em desvantagem, mas travam uma intensa batalha ${ }^{149}$. Castracani finge um recuo para trocar suas unidades de batalha, empurrando os aliados de Florença novamente para o rio.

Todavia, a Fortuna, inimiga de sua glória, retira-lhe a vida ${ }^{150}$. Segundo Machiavelli, uma brisa, sempre pestilenta do Arno, causou febre terminal a Castracani ${ }^{151}$. Após os enormes esforços em batalha, o comandante esperou para saudar suas tropas diante da iminente vitória e lhes infundir ânimo. Desengano pelos médicos, chama Pagolo Guinigi, de quem havia se tornado tutor. Em seu discurso de despedida, assevera que a Fortuna deseja torna-se árbitro de todos os assuntos humanos, impossibilitando-o de conhecer de antemão seus desígnios e o impedindo de superar suas ações ${ }^{152}$. Se estivesse ciente que não lograria êxito em suas ambições, buscaria outros meios para administrar os reinos que eles possuíam, pois: os príncipes de Milão e o imperador não são confiáveis, pois estão distantes ${ }^{153}$; os florentinos estão irados após tantas e ardorosas batalhas ${ }^{154}$; Pistóia está dividida e não possui fidelidade a eles ${ }^{155}$; os habitantes de Pisa são volúveis e cheios de falácias, ainda que possam estar sob a servidão jamais consentiriam em um domínio de Lucca ${ }^{156}$; por fim, a cidade natal de ambos não estará contente de estar sob o domínio do herdeiro de Castracani ${ }^{157}$. Nessas circunstâncias, pondera que agiria de maneira distinta, buscando um menor domínio, porém mais estável, com menos inimigos e menores invejas em uma tentativa de maior tranquilidade e menores conflitos ${ }^{158}$. Contudo, em vista das experiências que viveram conjuntamente, Castracani orienta a Pagolo a somente confiar em sua própria industria, na memória de sua Virtù e na reputação da vitória obtida ${ }^{159}$. Requer-se, portanto, prudência para buscar um acordo com os florentinos. Mistura-se a vida relatada de Castracani e seu exemplo ao relato do historiador, também analista político, Machiavelli, pois o condottiere ressalta ter deixado um reino e também ensinado a mantê-lo ${ }^{160}$. Deve-se aprender

\footnotetext{
${ }^{148}$ CC XXX. Acreditava que os resultados seriam similares, aniquilando definitivamente as obstruções ao seu domínio: “Castruccio, dall'altra parte, sentendo el grande esercito che $i$ Fiorentini gli avieno mosso contra, non sbigottito in alcuna parte, pensò che questo fusse quel tempo che la fortuna gli dovesse mettere in mano lo imperio di Toscana, credendo che gli inimici non avessero a fare migliore prova in quello di Pisa che si facessero a Serravalle, ma che non avessino già speranza di rifarsi come allora".

149 CC XXXI.

${ }_{150}$ CC XXXII. Machiavelli, novamente, inclui suas observações políticas no relato biográfico e histórico, pois expõe que somente a morte poderia impedir as realizações para as quais Castracani estava destinado. Quando a Fortuna deveria dar-lhe vida, retira-a: " Ma la fortuna, inimica alla sua gloria, quando era tempo di dargli vita, gliene tolse, e interruppe quelli disegni che quello molto tempo innanzi aveva pensato di mandare ad effetto, né gliene poteva altro che la morte impedire".

${ }^{151}$ CC XXXII "Donde che, stando esposto a uno vento che il più delle volte a mezzo dì si leva di in su Arno, e suole essere quasi sempre pestifero, agghiacciò tutto".

${ }^{152} \mathrm{CC}$ XXXII, “Ma la fortuna, che vuole essere arbitra di tutte le cose umane, non mi ha dato tanto giudicio che io l'abbia potuta prima conoscere, né tanto tempo che io l'abbi potuta superare".

${ }^{153}$ CC XXXII "Negli principi di Milano e nello imperadore non puoi confidare, per essere discosto, pigri, e gli loro soccorsi tardi"

${ }^{154} \mathrm{CC}$ XXXII "Hai per vicini e' Fiorentini, offesi e in mille modi da noi ingiuriati e non spenti; ai quali sarà più grato lo avviso della morte mia, che non sarebbe lo acquisto di Toscana".

${ }^{155}$ CC XXXII "Pistoia ancora ti resta, poco fedele, per essere divisa, e contro al sangue nostro dalle fresche ingiurie irritata".

${ }^{156}$ CC XXXII "Rimanti Pisa, dove sono uomini di natura mobili e pieni di fallacia; la quale ancora che sia usa in varii tempi a servire, nondimeno sempre si sdegnerà di avere uno signore lucchese".

${ }^{157} \mathrm{CC}$ XXXII “E' ti rimane la città di Lucca, la quale non sarà mai bene contenta di vivere sotto lo imperio tuo".

${ }^{158}$ CC XXXII. Desse modo, conjectura uma vida menos belicosa e com soluções mais diplomáticas para o estabelecimento de um controle menor, porém estável e traquilo: "Se io avessi creduto, figliuolo mio, che la fortuna mi avesse voluto troncare nel mezzo del corso il cammino per andare a quella gloria che io mi avevo con tanti miei felici successi promessa, io mi sarei affaticato meno e a te arei lasciato, se minore stato, meno inimici e meno invidia. Perché, contento dello imperio di Lucca e di Pisa, non arei soggiogati e' Pistolesi e con tante ingiurie irritati e' Fiorentini; ma, fattomi e l'uno e l'altro di questi dua popoli amici, arei menata la mia vita, se non più lunga, al certo più quieta, e a te arei lasciato lo stato, se minore, sanza dubbio più sicuro e più fermo".

${ }^{159}$ CC XXXII "Non dei pertanto sperare in alcuna cosa, fuora che nella tua industria e nella memoria della virtù mia e nella reputazione che ti arreca la presente vittoria".

${ }^{160} \mathrm{CC}$ XXXII "E arai ad avere meco duoi oblighi: l'uno, che io ti ho lasciato questo regno; l'altro, che io te lo ho insegnato mantenere".
}

ASSIS, Jean Felipe de. A díade virtù-fortuna na fundação e manutenção da ordem em Niccolò Machiavelli. Griot : Revista de Filosofia, Amargosa - BA, v.20, n.2, p.309-331, junho, 2020. 
com a vida e com o relato da vida de Castruccio Castracani, pois é necessário conhecer a si mesmo e saber misturar a força do ânimo pessoal com a potência das ordens civis sob seu comando $^{161}$. Enquanto Castracani cercava-se de inimigos em todas as esferas, imaginando alcançar gradativamente mais poder e glória, esse sugere a Pagolo Guinigi construir amizades que renderão segurança e conforto ${ }^{162}$. Apreende-se da vida de Castracani, das ações da Fortuna e de seus conselhos a Pagolo que o humano virtuoso deve estar preparado tanto para a guerra bélica quanto para a paz diplomática ${ }^{163}$. Evidencia-se, portanto, que mesmo um personagem, inicialmente favorecido pela Fortuna e pleno de Virtù em suas ações, não escapa às ações imponderáveis dos acontecimentos. Com grande astúcia e indústria supera seus inimigos em condições de extrema adversidade, podendo ser comparado a Felipe da Macedônia e Cipião. Todavia, é impossibilitado de atualizar seus intentos por não possuir as mesmas "pátrias" que esses $^{164}$.

A partir dos exemplos históricos selecionados ao longo do corpus de Machiavelli, constata-se a necessária ação humana, plena de Virtù, para o estabelecimento das ordenações civis e as medidas necessárias para a sua manutenção. A Díade Fortuna-Virtù é atestada em argumentações centrais do pensador florentino, associando-se às ocasiões e as ações imprescindíveis para o agir humano na história. A instabilidade política, as forças além do controle humano, a imponderabilidade das ações civis são temas recorrentes nas concepções sobre a Fortuna em variadas argumentações de Machiavelli. Em aberto diálogo com os humanistas cívicos que enfatizam maior participação política e social, mesclando embasamento racional, consideração moral e as discussões sobre as formas de governo, esse escritor apresenta uma concepção historiográfica a revigorar tradições do mundo antigo na criação de uma ordem civil mediante a Virtù, que demanda comprometimento pessoal e público, na exaltação das potencialidades e dos limites humanos.

\footnotetext{
${ }^{161}$ CC XXXII "È cosa in questo mondo di importanza assai cognoscere se stesso, e sapere misurare le forze dello animo e dello stato suo"

${ }^{162}$ CC XXXII "I quali dove io cercavo di farmi inimici, e pensavo che la inimicizia loro mi avessi a recare potenza e gloria, tu hai con og ni forza a cercare di fartegli amici, perché la amicizia loro ti arrecherà securtà e commodo".

${ }_{163} \mathrm{CC}$ XXXII "e chi si cognosce non atto alla guerra, si debbe ingegnare con le arti della pace di regnare".

${ }^{164}$ CC LXXII. È visto como forte, audaz, inabalável, buscando a vtória por todos os meios possíveis, sem se importar em usar fraudes e força, mas sem os meios necessários para a sua plena efetivação. "E perché vivendo ei non fu inferiore né a Filippo di Macedonia padre di Alessandro, né a Scipione di Roma, ei morì nella età dell'uno e dell'altro; e sanza dubbio arebbe superato l'uno e l'altro se, in cambio di Lucca, egli avessi avuto per sua patria Macedonia o Roma".
} 


\section{Referências}

BARON, Hans. The Crisis of Early Italian Renaissance. Princeton: Princeton University Press, 1993

BELL, Sinclair. Role Models in the Roman World: Identity and Assimilation. Ann Arbor: Michigan Press, 2008.

Benner, Erica. Machiavelli`s Ethics. Princeton: Princeton University Press, 2009

BIGNOTTO, Newton. A Antropologia Negativa de Maquiavel. Analytica v.12, n.2, p. 77-100, 2008.

Bignotto, Newton. Maquiavel Republicano. São Paulo: Loyola, 1991,

BOETHIUS. The Consolation of Philosophy. Cambridge: Harvard University Press, 1978.

BONADELLA, Peter. Castruccio Castracani: Machiavelli's Archetypal Prince. Italica v.49, n.3, p.302-314, 1972.

BONADELLA, Peter. Machiavelli and the Art of Renaissance History. Detroit: Wayne State University Press, 1973.

BROUCKE, Pieter. Tyche and Fortune of Cities in the Greek and Roman World. Yale University Art Gallery Bulletin, p. 33-49, 1994.

BRUCKER, Gene. Renaissance Florence. Berkeley: University of California Press, 1983

CANTER, H.V. Fortuna in Latin Poetry. Studies in Philology v.19, n.1, p. 64-82, 1992.

CHAPLIN, Jane. Livy's Exemplary History. New York: Oxford University Press, 2000.

CIOFFARI, Vincenzo. The function of Fortune in Dante, Boccaccio and Machiavelli. Italica v.24, n.1, p. 1-13, 1947.

DANTE, Alighieri. Opere. Bologna: Nicola Zanichelli, 1966.

de ASSIS, Jean. "Acaso, Chance, Fortuna e Azar: Imagens da Tyche no pensamento grego antigo" Fragmentos de Cultura 29.2 (2019): 301-309.

Frakes, Jerold. The Fate of Fortune in the Early Middle Ages: The Boethian Tradition. Leiden: Brill, 1988.

GARIN, Eugenio. L’Umanesimo Italiano: Filosofia e Vita Civile Nel Rinascimento. Editori Laterza, 1978.

GILBERT, Felix. On Machiavelli’s Idea of Virtu. Renaissence News v.4, n.4, p. 53-55, 1951.

LEFORT, Claude. Machiavelli in the Making. Evanston: Northwestern University Press, 2012,

MACHIAVELLI, Niccolò. Tuttele opere di Niccolò Machiavelli a cura di Francesco Flora e di Carlo Cordiè. 2 volumi. Milano: Arnoldo Mondadori Editore, 1949.

MANSFIELD, Harvey. Machiavelli's Virtue. Chicago: The University of Chicago Press, 1998.

POCOCK, J. G. A. The Machiavellian Moment: Florentine Political Thought and the Atlantic Republican Tradition. Princeton University Press, 1975.

POLLITT, J.J. An Obsession with Fortune. Yale University Art Gallery Bulletin, p. 12-17, 1994.

PRICE, Russell. Ambizione in Machiavelli's Thought. History of Political Thought v.3, p. 383445, 1982.

PRICE, Russell. The Senses of Virtù in Machiavelli. European Studies Review v.3, p.315-345, 1973.

PRICE, Russell. The Theme of Gloria in Machiavelli. Renaissance Quarterly v.30, n.4, p. 588$631,1977$.

ROLLER, Matthew. Models from the Past in Roman Culture: A World of Exempla. Cambridge: Cambridge University Press, 2018. 
SKINNER, Quentin. The Foundations of Modern Political Thought: Volume 1, The Renaissance. Cambridge: Cambridge University Press, 2002.

SKINNNER, Quentin. Visions of Politics: Renaissance Virtues. New York: Cambridge University Press, 2004.

van EGMOND, Bart. Augustine's Early Thought on the Redemptive Function of Divine Judgment. New York: Oxford University Press, 2018.

VIROLI, Maurizio, O Sorrido de Nicolau: História de Maquiavel. São Paulo: Estação Liberdade, 2002.

VIVANTI, Corrado. Nicolau Maquiavel nos Tempos da Política. São Paulo: Martins Fontes, 2016.

WHITFIELD, J.H. The Anatomy of Virtue. The Modern Language Review v.38, n.3, p. 222$225,1943$.

Autor(a) para correspondência: Jean Felipe de Assis, Universidade do Estado do Rio de Janeiro, Rua Alexandrina 288, Rio Comprido, 20261-232, Rio de Janeiro-RJ, Brasil. jeanfelipe@hcte.ufrj.br 